Energy \& Environment Division Lawrence Berkeley Laboratory UNIVERSITY OF CALIFORNIA

$$
\begin{aligned}
& \text { REOEilio } \\
& \text { ANG Og } 100 \\
& \text { OSTI }
\end{aligned}
$$

\title{
Indoor Environment Program 1992 Annual Report
}

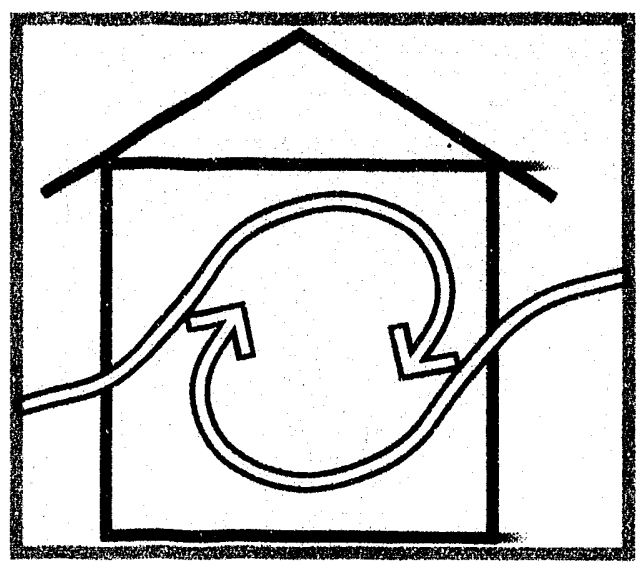


Available to DOE and DOE Contractors from Office of Scientific and Technical Information P.O. Box 62, Oak Ridge, TN 37831

Prices available from (615) 576-8401

Available to the public from

National Technical Informatior: Service

U.S. Department of Commerce

5285 Port Royal Road, Springfield, VA 22161

Prepared for the U.S. Department of Energy under Contract No. DE-AC03-76SF00098

Printed on recycled paper using vegetable-based inks 


\title{
Indoor Environment Program 1992 Annual Report
}

Joan M. Daisey, Program Leader

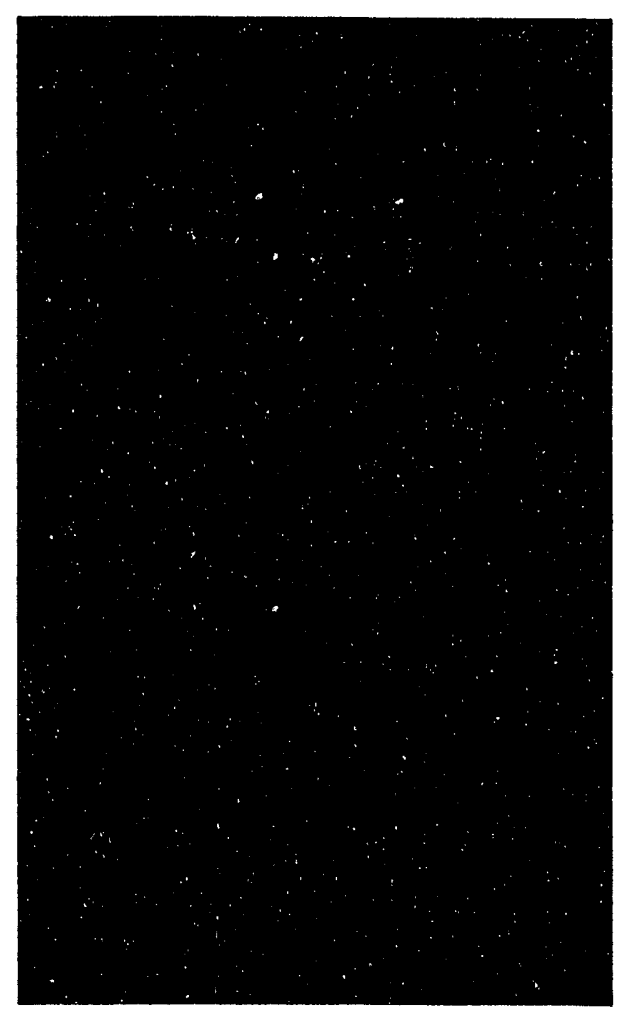

\author{
Energy \& Environment Division \\ Lawrence Berkeley Laboratory \\ University of California \\ Berkeley, California 94720 \\ (510) 486-5001
}

Report No. LBL-33442

\section{MASTER}




\section{Contents}

\section{Introduction}

\section{Energy Performance and Ventilation in Buildings}

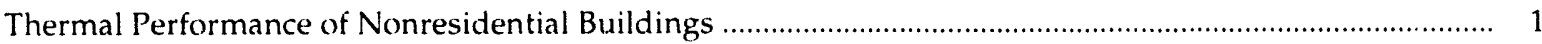

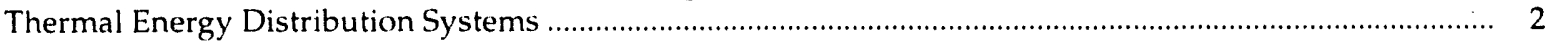

Alternatives to Compressor Cooling for Residences:

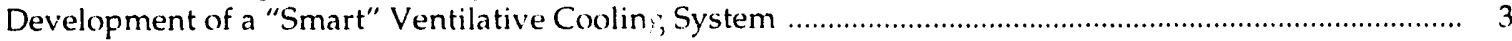

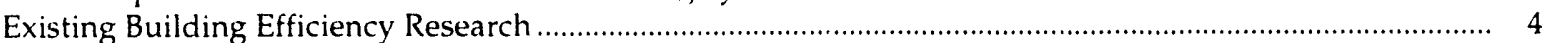

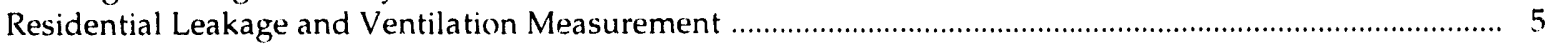

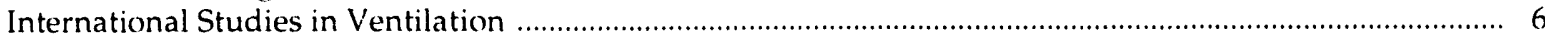

- Physical and Chemical Characterization of Indoor Air Pollutants

Comparison of Methods for Measuring Concentrations of

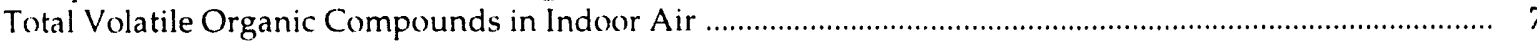

Chemical Characterization of Enviromental Tobacco Smoke ................................................................. 8

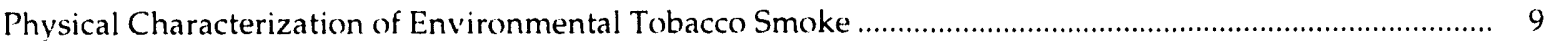

Development of a New Integrated Organic Vapor Particle Sampler for Polycyclic

Aromatic Hydrocarbons in Indoor Air and Environmental Tobacco Smoke ........................................ 10

Modeling Emissions of Volatile Organic Compounds from New Carpets ................................................ 12

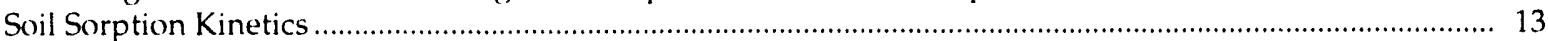

Pollutant Emission Rates from a Radiant Fiber-Matrix Gas Burner ................................................... 14

\section{Indoor Radon Research}

A Comparison of Modeled and Measured Soil-Gas Entry into an Experimental Basement .....

A Dynamic Pressure Technique for Estimating Permeability and Anisotropy of Soil to Airflow

Over a Scale of Several Meters

Relative Effectiveness of Subslab Pressurization and Depressurization Systems for Indoor

Radon Mitigation: Studies with an Experimentally Verified Model

Impact of Subslab Ventilation on Residential Ventilation Rates and Energy Costs ................................ 20

Statistically Based Methodologies for Identifying High-Radon Areas of the United States ......................... 21

\section{Indoor Air Quality Controls}

The Pollutant Control index: Progress Toward a New Method of

Characterizing Ventilation in Commercial Buildings

Use of an Air Vest to Reduce Worker Exposure and Improve Energy Efficiency in Industrial Fume Hoods

\section{Indoor Air Exposure and Risk}

Issues in Evaluating Risks and Control Strategies for Radon and Other Indoor Pollutants

Indoor Ozone Exposure and Energy Conservation .....

Hypothesis-Based Research on the Causes of "Sick Building" Symptoms:

A Design for Phases 2 and 3 of the Californin Henlthy Building Study ................................................. 28

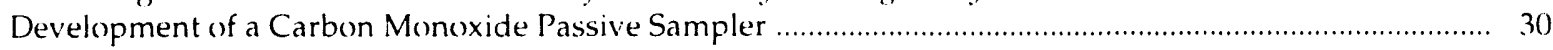

Biologically Based Risk-Assessment Models ................................................................................ 30 


\section{Introduction}

\section{$\mathrm{A}$ pproximately $38 \%$ of the energy consumed in the United States is used in} buildings. Reduction of infiltration and ventilation in buildings holds great potential for saving energy since the energy use associated with conditioning and distributing ventilation air is about 5.5 quads per year. However, since ventilation is the dominant mechanism for removing pollutants with indoor sources, reduction of ventilation can have adverse effects on indoor air quality, and on the health, comfort and productivity of building occupants.

The Indoor Environment Program in the Ente...' and Environment Division at LBL was established in 1977 to conduct integrated research on ventilation, indoor air quality and energy use and efficiency in buildings for the purpose of increasing energy efficiency in buildings while maintaining or improving occupant health and comfort. The Program is part of the Center for Building Science at LBL. Research is conducted on buildings energy use and efficiency, ventilation and infiltration, and thermal distribution systems; on the nature, sources, transport, transformation and deposition of indoor air pollutants; and on exposure and health risk associated with indoor air pollutants. Pollutants of particular interest include radon; volatile, semi-volatile and particulate organic compounds; and combustion emissions, including environmental tobacco smoke, CO, and NO.

Research on exposure and risk analysis for indoor air pollutants provides a broad perspective on indoor air quality and associated health and comfort risks. It also helps to establish the relative significance of various categories of pollutants and to focus research efforts. New exposure metrics and risk assessment methods, based on understanding of fundamental biological processes, are developed as part of this effort.

Studies of whole buildings are undertaken in field experiments. Relationships between human health comfort and productivity and environmental and building factors are investigated in such studies. Whole building field studies are also undertaken to understand building and subsystem dynamics with respect to energy and air movement and to develop representative databases of building characteristics for modeling energy use in U.S. buildings as well as population exposures to indoor pollutants.

Air infiltration and entilation rates are measured and modeled for residential and commercial buildings in order to understand energy transport and thermal losses from various components of building shells and ventilation systems. Methods for reducing energy losses are developed based on these studies. The effectiveness of various ventilation sys- tems for pollutant removal is also investigated. Methods for characterizing ventilation and building energy use are developed for experimental and applied uses.

Indoor air quality studies focus on understanding the dynamic processes within buildings which control pollutant sources, transport, transformation, deposition, re-emission and removal. Spatial and temporal variability of pollutants are also characterized. This research provides the basis for developing models for population exposures to various types of pollutant exposures.

Research on control techologies and strategies is directed toward development of those which are the most costand energy-efficient for each class of pollutant. Since source controls are often the most effective and energyefficient method for improving indoor air quality, emissions from various types of indoor sources (combustion sources, building and furnishing materials, consumer products, office equipment, etc.) are characterized with respect to chemical composition and rates of emission. Entry of soil gases, containing radon and oryanic pollutants, into buildings is investigated through modeling and field measurements. The effects of ventilation and other control methods or: source strengths and energy usage are also investigated and evaluated.

\section{Program Staff}

Joan M. Daisey, Program Leader

Anthony V. Nero, Deputy Program Le'ader

Michael G. Apte

Anne Baughman*

Fred S. Bauman'

Frederic Y. Bois

Yv'es Bonnefous*

Gail Schiller Brager'

Wolfgang Browa*

A. Cano-Ruiz*

Remi Carrie*

Lilian R. de Carvalho'

Penelope J.E. ComptonQuintana

\section{-Student}

Participating Guests

'Faculty Scientist

'Group Leader
Joyce Cordell

Richard Diamond

Darryl Dickerhoff

Juergen Dieris*

Anushka Drescher*

David Faulkner

Helmut Feustel

William J. Fisk

Sharon Fuller

Ashok J. Gadgil

Karına Garbesi*

Hans-Peter Graenicher*

Lara A. Gundel

Magnus Herrlin*

Peter Hochlein*

Alfred T. Hodgson

Nori Hudson

Richard Jansky
David Jump
Mandy Kamangar
Andreas Klinger*
Dung Kong*
Claude Khalizadeh
Hans-Georg Kula'
Victor Lee*
Tsair-Fuh Lin*
John C. Little
R.K.K Mahanama
Robert Meierhans'
Rene Meldem*
Mark J. Mendell*
Shelly Miller Leiden*
Mark Modera
William Nazaroff'

Matty Nematollahi

Kasumittie Nitta ${ }^{+}$

Timothy Nuzum

Richard J. Prill

Steve Rein*

Thomas Reitzel*

Kenneth L. Revzan

UIf Riemann*

Allen Robinson*

Rosa Rodriguez

Tonn Sasset

Richard G. Sextro

Max Sherman

Brian Smith

Martyn T. Smith

Robert C. Spear'

Corina Stetiu'
Carol Stoker

Bettina Stracke*

Eugene Suhh*

Dou; Sullivan

JoAmi ren Brinke*

Tracy Thatcher*

Andicas Theiss*

Chuong Tran*

Gregory W. Traynor

Burke Treidler

John Ulvoy*

Frietjof Unander* Charles 1. Weschler

Bernd Wildmoser*

Alicia L. Woods*

John D. Wouley 


\section{Energy Performance and Ventilation in Buildings}

\section{Thermal Performance of Nonresidential Buildings}

Cooling of nonresidential buildings contributes significantly to consumption of electrical energy and to peak power demand. This energy consumption can be reduced by reducing the cooling load of the building, reducing the requirements of mechanical cooling, or improving thermal distribution within the building.

The fans used to transport cool air through the ducts consume a significant amount of electrical energy used to cool buildings. If ventilation and thermal conditioning of buildings are separated, the amount of air transported through buildings can be reduced significantly. In this case, cooling is provided by radiation, using water as the transport medium (hence these systems are called "hydronic"), and the ventilation is provided by outside air systems without having to recirculate air. Not only does this improve comfort conditions, it increases indoor air quality and improves the control and zoning of the system. Due to the physical properties of water, radiant cooling systems can remove a given amount of thermal energy for pumping using less than $5 \%$ of the otherwise necessary fan energy. Although the fresh air necessary for ventilation will still be distributed through ducts, the electrical load for duct fans can be reduced to approximately only $25 \%$ of the original.

Compared with conventional "allair" systems, hydronic cooling systems have these advantages:

- Due to the large surfaces available for the heat exchange, the coolant temperature is only marginally lower than the room temperature. This allows the use of either heat pumps with high COP values or alternative cooling sources.

- Hydronic cooling systems reduce problems caused by duct leakage, as the ventilation air has significantly reduced flow and is conditioned to equal the room temperature rather than the typical cooling supply air temperatures.

Hydronic cooling systems together with heavy construction can reduce peak cooling power demand significantly. The thermal storage of high structural mass helps to shift the peak building cooling to off-peak hours and allows the use of night cooling to further reduce compressor cooling.

A different approach for reducing the energy consumption in non-residential buildings is to use an economizer. Air economizers decrease the requirements of mechanical cooling by using cool outdoor air instead of mechanically cooled air. If outside air is cool enough, the outdoor air and recirculated air are mixed to maintain the desired supplyair temperature necessary to remove the cooling load. If the desired supplyair temperature cannot be maintained by mixing the two air streams, the supply air is cooled mechanically. Outdoor airflow is reduced to its minimum if the outside air conditions are judged worse than those of the return air.

Our work shows that the use of an air economizer improves the energy efficiency of conventional air handling systems thai supply constant airflow; however, no economizer control strategy works best under all circumstances. Different criteria must be used in dry and humid climates to decide when the outside air supply should be reduced to a minimum.

Detailed studies for buildings in moderate climates show that mechanical cooling may become redundant if the envelope is improved, the thermal storage performance is increased, and the air-handling system is equipped with an economizer.

$\begin{array}{ll} & \text { Investigators } \\ \text { H.E. Feustel } & \text { P. Hoehlein } \\ \text { B.V. Smith } & \text { H.-G. Kula } \\ \text { C. Stetiu } & \text { B. Wildmoser } \\ \text { H.-P. Graenicher } & \end{array}$




\section{Thermal Energy Distribution Systems}

Thermal-energy distribution systems represent the vital link between heating and cooling equipment and conditioned building spaces. In the United States, approximately 10 quads of primary energy annually passes through generally inefficient thermal distribution systems in buildings. Moreover, the load shape due to inefficient distribution systems is often more peaked than general space cooling demand, implying that distribution efficiency improvements can provide even larger savings in peak electricity demand.

In FY 1990, we initiated a multiyear research program that focused on improving the efficiency of thermal energy distribution systems. Cosponsored by the California Institute for Energy Efficiency and by the Department of Energy, this program consists of research projects focusing on residential air distribution systems (summarized below), on localized distribution systems, on direct cold-air distribution systems, and on friction-reducing additives for hydronic distribution systems in commercial buildings (being performed at UC Santa Barbara).

\section{Improving Residential Air Distribution Efficiency}

In FY 1991 our research on residential air-distribution efficiency focused on characterization of field performance, development and refinement of simulation tools, and evaluation of the national energy savings potential of improving thermal distribution systems in residences. In FY 1992 our focus was shifted toward solving the problems identified with these distribution systems. Our efforts included: 1) technology development, 2) development of efficiency-improvement protocols, 3) analysis of system / building/equipment interactions, and 4) development of a framework for characterizing the performance of residential distribution systems.

Regarding technology development, our most significant result was the proof of concept of an aerosol-based technology that can seal ducts from the inside. This technology should be able to remotely seal inaccessible ducts, and simplify the sealing process in moderately accessible systems. Laboratory experimentation and theoretical modeling was used to define the appropriate techniques for maximizing sealant delivery to the leaks, and lab experiments confirmed that leaks of 3-5 $\mathrm{mm}$ in diameter located 3-5 meters from the aerosol injection point could be sealed within 10 minutes. Regarding protocol development, both new and existing building protocols were developed this year. For new construction, a duct leakage commissioning protocol was tested in 20 houses. This protocol is based on direct pressurization of the duct system during the rough-framing construction stage, at which time leaks are still accessible. We found that, using this technique, the leakage of these systems could be reduced by $50 \%$ on average within 30 minutes.

Two manufacturers are now marketing devices specifically designed for this type of commissioning. For existing construction, we worked with a local electric utility to develop a protocol for retrofitting residential duct systems. This protocol includes insulation as well as sealing, and may also include installation of a return-plenum whistle to indicate when air filters are dirty. This protocol will be field tested in FY93, including direct measurements of the interactions between duct improvements and the heating/cooling equipment. A major accomplishments this year was the development of a potential framework for rating the efficiency of residential distribution systems. The objective of this effort was to develop a yardstick by which the efficiencies of alternative distribution systems could be compared. The yardstick developed can be used to compare the efficiencies of ducts located in attics with those located in crawl spaces or basements, as well as with hydronic distribution systems. Interactions between distribution system performance and heating/cooling equipment are accounted for, as is the energy used for transport. This effort relied heavily on our detailed simulation tool, which was used to separate out the direct effects of distribution efficiency improvements fiom interactive impacts. Future efforts will include field measurements to determine all of the components of this Figure of Merit (yardstick), as well as comparisons with other detailed simulation tools.

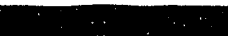

Investigators

M. Modern

F. Carric

R. Jansky

D. Jump

B. Treidler 


\section{Alternatives to Compressor Cooling for Residences: Development of a "Smart" Ventilative Cooling System}

Ventilation has been identified as the prime candidate to replace compressor cooling in moderate climates. Two ventilation methods are being considered: 1) direct cooling ventilation where ventilation air is supplied when cooling is desired, and 2) thermal storage ventilation where ventilation air is supplied primarily during non-cooling periods to reduce the temperature of the thermal mass of the building.

Direct cooling ventilation works by removing internal heat gains. The cooling effect of direct ventilation is enhanced because people feel cooler when air is moving over them. This is in part a result of air motion increasing the rate of evaporation from the skin. The direct cooling method is used typically in climates that are not extreme (outdoor temperatures below $32^{\circ} \mathrm{C}$ ) and that have small diurnal temperature swings (less than $10 \mathrm{~K}$ ).

Thermal storage ventilation works well in climates with large diurnal temperature swings. Air is supplied to the building during cool periods, both cooling the indoor air and storing "coolth" in the structure. Ventilation is reduced when the outdoor temperature rises. The indoor temperature rises more slowly than the outdoor temperature because the cool structure absorbs heat from the indoor air. Thermal energy storage is a means of accommodating delay between the availability of cooling resources and the need for building cooling load. Both the charging and discharging of the storage medium can be either passive or active.

The passive/passive case corresponds to thermal storage ventilation (cool night air removes heat from the structure and then the structure absorbs heat during the day). A passive/active combination may be used when night air is too cold for continuous night ventilation of the structure. The cold air can be directed to an isolated storage medium and then, when necessary, heat can be absorbed by the medium. Both methods of ventilation cooling may be either natural or induced. Induced ventilation must be used when the natural driving forces are inadequate or when the large openings in the building enveiope that are required for natural ventilation would create an unacceptable security problem. Induced ventilation is also easier to control using electro-mechanical devices.

Control of many of the alternative systems is inherently more complex than compressor cooling. Ventilation can be difficult to control manually. Ventilation systems should be off when the outdoor temperature is higher than the indoor temperature. Automatic control of ventilation requires at least a knowledge of both the indoor and the outdoor temperatures and optimal control requires information about humidity, time of day, heat capacity of the residence, etc. The control problem is more complicated when ventilation is combined with other strategies (e.g., evaporative cooling).

Although ventilative cooling has the potential to replace compressor cooling in transition climates, certain requirements have to be met by the building envelope to guarantee the success. A parametric study using a building simulation model that incorporates modules for each strategy will be used to ideniify the most promising envelope measures.

\section{Investigators}

H.E. Feustel 


\section{Existing Building Efficiency Research}

This research is part of the DOEHUD initiative launched in response to the National Energy Strategy's directive to improve the energy efficiency in public housing. Under the Initiative's guidance a collaborative project has been established to demonstrate energy efficiency in public housing as part of a utility's demand side management (DSM) program. The partners in this project include the U.S. DOE Boston Support Office, the Boston Edison Company, the Chelsea Housing Authority, with technical support from the Citizens Conservation Company and two national laboratories, ORNL and LBL. The demonstration site is the Margolis Apartments, a 150-unit high-rise apartment building for the elderly and handicapped, located in Chelsea, Massachusetts, in the greater Boston metropolitan area.

As part of the technical assessment of the project, LBL conducted a fourday survey to measure the ventilation and infiltration rates of the Margolis Apartments. The primary objective of the survey was to collect the necessary data in order to characterize the impact of air leakage retrofits on energy use and air quality in a modern highrise apartment building.

The Margolis Apartments building was designed in 1973-1974 and is typical of high-rise construction from that period. The building has thirteen stories and is of concrete bearing-wall construction. The individual apartments have electric resistance heaters, double-pane windows, and mechanical exhaust ventilation in the kitchen and bathroom.

The kitchen and bathroom fans for each apartment are exhausted into separate vertical shafts that have exhaust fans located on the roof. The supply air system for the building is provided by a fan and heating unit on the roof that connects to a vertical shaft that has supply registers to the main hallway on each of the floors. We measured the air leakage in nine apartments using blower doors. In three of these apartments we measured the leakage to the adjacent units, either to the neighboring apartment or to the one above or below. Leakage to each side-by-side unit was about $2 \%$ of the total. Leakage to an apartment either above of below was about $8 \%$ of the total. Leakage to the hallway was estimated to be about $4 \%$ of the total. These values are similar to the results from measurements of other new apartment buildings.

None of the roof-mounted exhaust fans were working at the time of our audit. We repaired two of the units and were able to make measurements of their performance. Measurements of the loads on the fan motors showed that they were running at about 50\% load except for the kitchen exhaust, which was at $170 \%$ of rated full load, probably due to bad bearings or a faulty motor. The motors used were $1 / 4$ HP while the designed specs call for $1 / 6 \mathrm{HP}$ motors. The fans themselves looked in good condition, although most of the $V$-belts that connected the motors to the fans were broken. It is possible that many of the exhaust systems could be made operational by simply replacing the $V$-belts and/or motors.

Ventilation rates were measured using tracer gas in two apartments in various configurations of exhaust ventilation. With no exhaust ventilation we found typical rates to be about 0.2 air changes per hour $(\mathrm{ACH})$. These ventilation rates are belowthe ASHRAE standards. Operation of the building supply system and the exhaust systems increased the ventilation rate to $0.44 \mathrm{ACH}$. If the mechanical ventilation systems were operating at their designed flows, the apartment ventilation rates might well meet the ASHRAE standard without excess ventilation. Operation of the apart. ment's kitchen exhaust fan indicates that it has a flow much larger than the designed value, while the bathroom exhaust fan is only somewhat larger than its design value.

We emphasize that these ventilation rates are valid only under the weather conditions found during these measurements. It is likely that there would be variations with the seasons and operation of other exhaust systems. In addition, units located in other parts of the building might experience very different ventilation rates. Measurement of the fraction of air that is coming from other apartments compared to outside was beyond the scope of the audit. For these and other reasons, we plan to model the building air flows using simulation programs.

Investigator

R.C. Diamond

D.J. Dickerhoff

H.E. Finstel

R. Jansky

M.H. Sherman 


\section{Residential Leakage and Ventilation Measurement}

Heat and mass transfer caused by pressure-driven airflow is an important process for determining environmental quality as well as energy requirements of buildings. Heat, moisture, and contaminants are all transported by air movement between the indoors and the outdoors as well as between different zones within a building. Appreciation of these airflows is critical to understanding the performance of buildings.

Although direct measurement of airflows can be made, it is more practical to use diagnostic properties of the house to calculate the airflows of interest.

The key diagnostic for air flow determinations is the air leakage. LBL has provided leadership in the development and standardization of air leakage measurement techniques for whole buildings, multiple spaces, and distribution systems. We work with the American Society for Testing and Materials (ASTM) to get the results of our research incorporated into consensus standards and thus to the user community.

LBL is currently working with ASTM committee E6.41 on developing or revising standards on both leakage and tracer gas measurement. Standard E779 on fan pressurization is currently under revision and standards on duct leakage and multizone leakage are under development. Standard E741 on the use of a single-tracer gas to measure ventilation is also under revision. Current work is focused on providing results suitable for publication in the proceedings of an ASTM-sponsored symposium (October 1993) which will ultimately be used during the standards process.

Whereas diagnostic techniques can be used to characterize the building, ventilation measurements are needed to determine how' the characteristics affect the air flows. Virtually all ventilation measurements use the dilution of a tracer gas. The majority of such measurements have been made for a single zone using a single tracer gas. In recent years, the need to determine ventilation rates/air flows in complex buildings has become more acute, and many researchers have been devoting an effort to the problem. LBL uses its Multi-Tracer Measurement System (MTSM) to make such measurements.

As part of a research project sponsored by the Electric Power Research Institute (EPRI), we have been measuring interzonal airflows in single-family and multifamily homes in the Pacific Northwest. These measurements are being used to assist in determining the accuracy of ventilation modeling and in the determination of distribution system effects. The data are currently being analyzed and combined with other data sets to be included in EPRI reports and in the upcoming ASTM symposium.

The test methods and characterization efforts are used by professional societies such as the American Society of Heating, Refrigerating and Air Conditioning Engineers (ASHRAE) to set standards of professional behavior through handbooks and design standards. We work actively with ASHRAE through its technical and standards committees.

Investigators

M.H. Sherman

D.J. Dickerhoff

M.P. Modern 


\section{International Studies in Ventilation}

The Conjunction of Multizone Infiltration Specialists (COMIS) workshop held at LBL coordinated a multinational team of experts to develop a multizone airflow model on a modular basis. The group at LBL focused on the output routines to maximize the final program's ease of use and the development of a Time Management System (TMS). The program has been linked to a spreadsheet program to use the graphics capabilities available for PC-type computers. Macros were developed to allow use of the available output options by users unfamiliar with the spreadsheet program. Additional output options to create tables for selected parameters were also installed.

Within the framework of an Annex adopted by the Energy Conservation in Buildings and Community Systems program of the International Energy Agency, we have been studying physical phenomena causing airflow and pollutant transport (e.g., moisture) in multizone buildings. Special emphasis is given to providing data necessary to use the COMIS model (e.g., wind pressure distribution, default values for leakage of building components, material properties like absorption and desorption). An important part of this annex is the comparison between model results and results from in-situ tests. Before these data sets can be used for model evaluation, however, internal model comparisons based on benchmark buildings must be performed.

The multinational experts comprising COMIS undertake different coordinated tasks including model development, data acquisition and analytical studies. The Annex is scheduled to span a fourand-a-half year period. To reach these objectives the project is divided into three subtasks:
- System development: A multizone air flow and pollutant transport modei is being developed on the basis of the COMIS model by developing flexible expert routines, incorporating additional modules, and developing user-friendly interfaces for input and output. The coupling with a thermal building simulation model will be demonstrated within this project.

- Data acquisition: Data sets are being obtained for evaluation and as input for the model.

- System evaluation: The model will be evaluated using data obtained from subtask 2 . Sensitivity of the model to the quality of input data will be determined.

Results of these subtasks will be presented to researchers and consultants. These results will assist in promoting energy-efficient building designs.

Close cooperation arnong the COMIS team-members is envisioned, mainly with regard to state-of-the art reviews, data collection, coordination of work, e.g., defining cases for evaluation with other pertinent projects. As part of its ongoing work plan, the Air Infiltration and Ventilation Centre (AIVC) will disseminate the results of this particular Annex. A database for evaluation has already been prepared by AIVC

Law rence Berkeley Laboratory is managing the Annex on behalf of the U.S. Department of Energy. By the end of FY 1992, Belgium, Canada, France, Italy, Japan, The Netherlands, Switzerland and the USA had officially committed to the Annex.

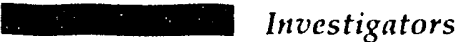
H.E. Felustel
A. Klingler
B.V. Smith
U. Riemann
P. Hochlein
R. Winkelmann 


\section{Physical and Chemical Characterization of Indoor Air Pollutants}

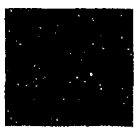

\section{Comparison of Methods for Measuring Concentrations of Total Volatile Organic Compounds in Indoor Air}

Increasing emphasis is being placed on the measurement of total volatile organic compounds (TVOC) as an indicator of indoor air quality. It has been hypothesized that such a mea. sure is a predictor of sensory irritation. The measurement of TVOC is also being used as a screening tool to determine if indoor environments are contaminated above typical levels.

There is currently no standard, or single, widely accepted method for TVOC measurement that is directly applicable to studies of indoor air quality. In the absence of standard methods, a variety of procedures have come into practice. Results can rary widely due to the different sampling, analytical, and tata analysis techniques that are employed.

This investigation compared a simple flame-ionization detector (FID) method for TVOC measurement with a previously published gas chromatography-mass spectrometry (GC-MS) method that is based on total-ion current relative response factors. A direct reading, infra-red gas monitor was also included in the comparison.

In laboratory experiments with eight known test atmospheres, the GC-MS method had good precision and acceptable accuracy when the measured and predicted compound concentrations were compared. The FID method, which primarily responds to carbon, demonstrated good precision and accuracy when the measured values, calculated as concentrations of carbon, were compared to the predicted corbon concentrations for the test atmospheres. For the infrared gas monitor, however, the ratios of the measured to predicted concentrations varied over two orders of magnitude.
It was concluded that the infrared gas monitor is an inappropriate tool for measuring TVOC in gas mixtures of varying and unknown composition.

Samples; of indoor air collected in a variety of buildings with different sources of volatile organic compounds were analved by both the FID and GC-MS methods, and the results were compared. When the results of both analyses were expressed as hydrocarbonequivalent concentrations, they were found to be similar and highly correlated, with the GC-MS values about $20 \%$ higher, on average. The comparison between the analyses is shown (Figure). In conclusion, the inherent simplicity and low cost of the FID method make it an attractive choice as a screening tool for TVOC.

Investigators A.T. Hodgson I.D. Wooley

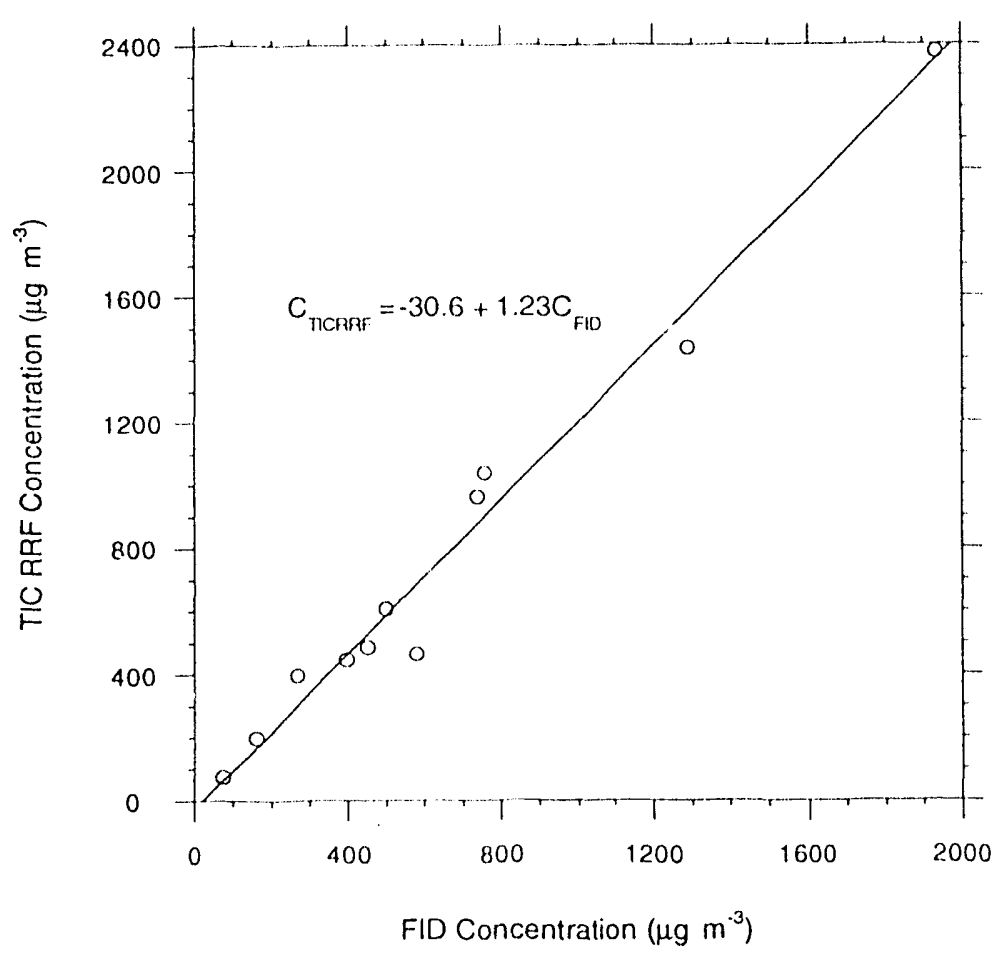

Figure.

GC-MS lotal-ion-current relative response factor (TIC RRF) measurements of TVOC as hydrocarbons versus FID measurements of TVOC for samples of indoor and ouldur air. 


\section{Chemical Characterization of Environmental Tobacco Smoke}

Environmental tobacco smoke (ETS) is a complex mixture of over 4000 chemicals distributed between the vapor and particulate phases. ETS consists of diluted and aged sidestream smoke emitted by the burning tobacco between puffs, with smaller contributions from exhaled smoke and smoke emitted into the room during puffs. Because approximately 50 million Americans are smokers, almost every non-smoker is expnsid to ETS to some degree. A growing body of scientific evidence shows that exposures to ETS increase risks of lung cancer, heart disease, respiratory infections in young children and exacerbation of asthma in children. Despite the significance of ETS exposures, chemical and physical characterization of the complex environmental mixture has been very limited and relationships between exposure and dose are not well understood.

Research is uilderway in the Indoor Air Chemistry Group to characterize the vapor-particle partitioning and particle size distributions of the polycyclic aromatic hydrocarbons (PAH) in ETS, under various environmental conditions. The purpose of this work is to increase understanding of the relationships a mong exposure, lung dosimetry and health risks of ETS exposidre. In order to determine vapor-particle partitioning and particlesize distribution of PAH in ETS, both sampling and analysis methods had to be developed. An analysis method for vapor and particulate PAH in ETS, which is both sensitive and selective, has been developed. The method requires about one milligram of material for analysis. Samples are extracted and then passed through silica to separate the PAH-containing fractions. The fractions are then analyzed by high pressure liquid chromatography with dual programmable fluorescence detectors. Limits of detection for individual PAH are of the order of 0.05 ng/gram of particulate matter. The relative precision of the method ranges from $4 \%$ to $19 \%$, depending upon incividual PAH.
As part of this research, an integrated organic vapor-particle sampler (IOVPS) has been developed. A sizeselective si'st impactor, with four size cuts between 0.1 and $1 \mu \mathrm{m}$ and a sampling rate of 40 to $50 \mathrm{~L} / \mathrm{min}$, has also been designed, constructed and is currently being tested. The impactor was designed so that samples of ETS sufficiently large for chemical analysis could be collected within a few hours. The impactor will be used to determine particle-size distributions of particulate $\mathrm{PAH}$ and other organic species in ETS.

In a second project initiated in August, 1992, emission factors are being determined for a wide range of toxic volatile organic compounds in simulated ETS and in fresh sidestream smoke from major brands of cigaiettes smoked in California. Measurements of aldehydes, $\mathrm{N}$-nitrosamines, 18 other volatile organic compounds, respirable particles, nicotine, $\mathrm{NO}$, and $\mathrm{CO}$ will be made in an environmental chamber. The effects of aging on emission factors for various compounds will also be investigated. The emission factors will be used to model California population exposures to toxic air pollutants from ETS and to identify those compounds for which ETS is the primary source of exposure.

Investigators

$$
\begin{aligned}
& \text { I. M. Daisey } \\
& \text { L. A. Gundel } \\
& \text { K.R.R. Mahanama } \\
& \text { S. V. Hering* } \\
& \text { Aerosol Dynamics, Inc. } \\
& \text { Berkeley, CA }
\end{aligned}
$$




\section{Physical Characterization of Environmental Tobacco Smoke}

One of the nost important factors affecting deposition of environmental tobacco smoke (ETS) particles in the lung is the particle size distribution. We are undertaking experimental studies to examine the effects of several indoor environmental parameters, such as ventilation rate, mixing or circulation rate, smoking rate, temperature and relative humidity, room size, and aging, on ETS particle-size distribution.

Numerous experiments have been conducted with Kentucky Reference cigarettes and several selected brands of commercial cigarettes in the Indoor Air Quality Research House. Sidestream smoke was generated by a surrogate smoker (cigarelte smoking machine) and an actual smoker. Both total and size-segregated particle concentrations were measured as a function of time using a condensation nucleus counter, a differential mobility analyzer, and an optical particle counter. The chamber environmental parameters inc uding relative humidity, temperature, and flow velocity were also measured during and after the experiments. The cilamber ventilation rate was determined by monitoring the decay of $\mathrm{SF}_{n}$ tracer gas concentration.

The observed ETS particle size distritution is fit reasonably well by the lognormal distribution. The geometric mean diameter, $d_{k}$, and the geometric standard deviation, $s_{k}$, have been cal-

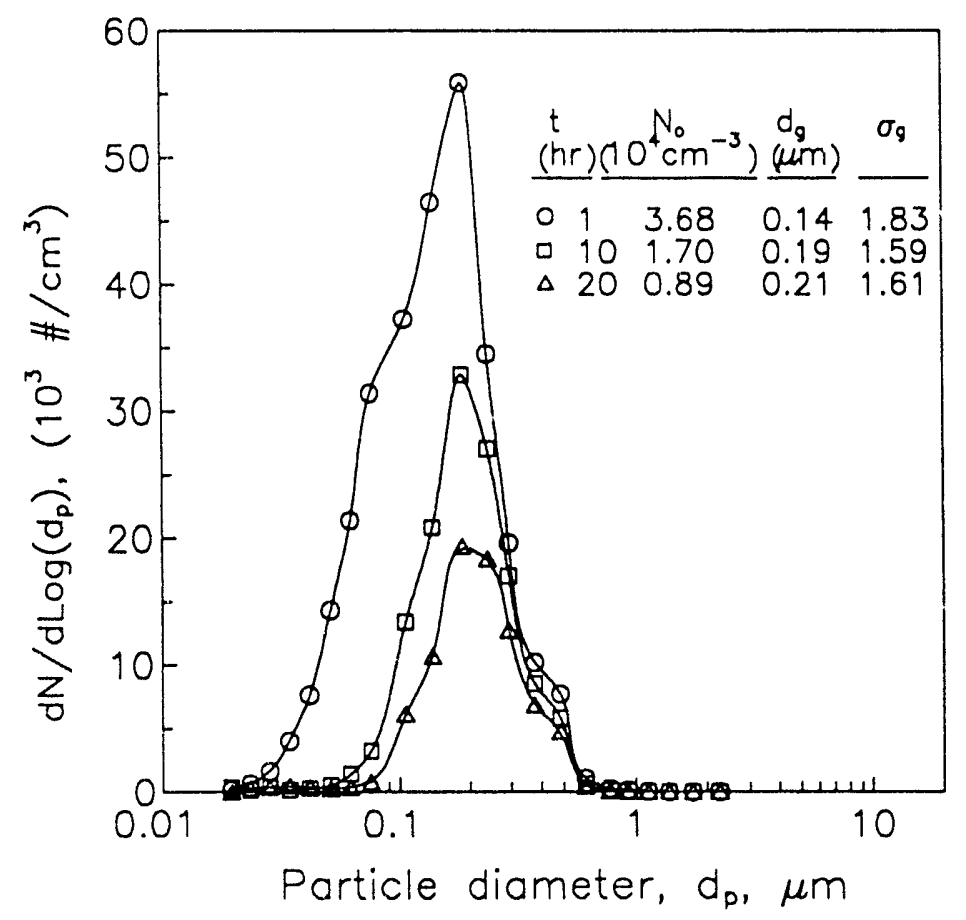

Figure.

Particle size distribution of envirommental tobacco smoke at different times after cigarrete is burned. $t=$ time after igniting cigarette; $N_{n}=$ toial number concontrationl; $d_{2}=$ geometric mean diameter; $\sigma_{i}=$ geometric standard devation.

culated by fitting the experimental data. The size distribution changes with time due to particle coagulation, deposition, and removal by ventilation. Initially, $d_{k}$ is $0.14 \mu \mathrm{m}$, with $s_{k}$ 1.83. After 10 hours, the mean size is larger, with $d_{k} 0.19 \mu \mathrm{m}$, and the size distribution is narrower, with $s_{k} 1.59$. Since the smaller particles coagulate to form the larger particles, the decay of smaller particles in the number concentration : $s$ faster than that for the larger particles (Figure).

Particle coagulation was simulated with a numerical model for various experimental conditions. For the case of low air exchange rate $(\sim 0.03 \mathrm{ACH})$ and natural mixing in the chamber, the particles with a size smaller than $0.25 \mu \mathrm{m}$ decrease and the larger particles increase in number concentrations by coagulation. However, the coagulation has very little influence on the particles with a size larger than $0.43 \mu \mathrm{m}$.

Removal of ETS particles by deposition on interior walls is dependent on particle size and air circulation. Higher air flow turbulence in the chamber can transport more particles to the wall and increase the deposition. Particle deposition rates were determined from the measured concentrations after correcting for the influence of coagulation and ventilation. It was found that the particles with the size from 0.2 to $0.4 \mu \mathrm{m}$ have the lowest deposition rates. Combining the information from coagulation and deposition, we may explain the observed number concentration peak that appears near $0.2 \mu \mathrm{m}$. 


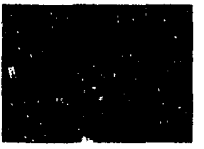

\section{Development of a New Integrated Organic Vapor Particle Sampler for Polycyclic Aromatic Hydrocarbons in Indoor A and Environmental Tobacco Smoke}

Accurate measurements of phase distributions of polycyclic aromatic hydrocarbons (PAH) in indoor air and environmental tobacco smoke (ETS) are needed in order to assess exposure to carcinogenic compounds, since lung deposition patterns of $\mathrm{PAH}$ depend on the distribution of the PAH between the gas and particle phases. Sampling for gas-phase organic polycyclic aromatic hydrocarbons (PAH) has depended on use of sorbent beds filled with XAD or Tenax resin beads. Since such beds follow filters, desorption of semi-volatile compounds from the filters or collection of gases by the filters can lead to incorrect measurements of gas-phase concentrations. To aroid these artifact problems we ha .e developed an integrated organic vapor-particle sampler (IOVPS; Fig. 1) based on a new XAD-4coated annular denuder, which strips the gas phase species from the airstream before collection of the particles on a Teflon-coated glass fiber or Teflon filter. An annular denuder is a glass cylinder with a glass rod tixed inside, forming an annulus through which air is pulled. The exposed surfaces of the annulus have beer, sandblasted and coated with ground XAD-4 resin. The coated annulus traps gas-phase species rather than particles because gas diffusion velocities are much faster than the particle diffusion velocities of the sampled air stream. In the IOVPS the gas phase components are adsorbed at the walls, but the particles are collected downstream of the denuder on a filter. A denuder or sorbent trap downstream of the filter collects any semi-volatile species which evaporate from the filter during sampling. The IOVPS makes possible determination of accurate phase distributions which are based on direct measurements of both gas and particle phase concentrations.

This year's efforts focused on developing the coating technique, refining analytical methods for the semi-volatile $\mathrm{PAH}$, and performing field tests of the IOVPS in indoor air. When a gaseous compound that is supposed to be trapped by a bed or filter is found downstream of the bed or filter, this is known as a "breakthrough." Breakthroughs occur most commonly for highly volatile compounds. The principal goal of the field testing program was to find optimum sampling conditions for minimum breakthrough of the semi-rolatile species naphthalene and its methyl derivatives. The naphthalenes are the most volatile of the semivolatile PAH. Breakthrough was evaluated by sampling indoor air and then determining $\mathrm{PAH}$ concentrations on each of three denuders which had been arranged in series upstream of a filter.
The percentage recovery on the first denuder is shown for the naphthalenes (Fig. 2) for flow rates of 5,10 and 20 $\mathrm{L} / \mathrm{min}$ and sampling times of 3 and 6 hours. Recovery decreased as flow rate and sampling time increased beyond $5 \mathrm{~L} / \mathrm{min}$ and 3 hours, respectively. Recovery increased as the molecular weight of the semi-volatile PAH increased. Even for $20 \mathrm{~L} / \mathrm{min}$, the total recovery of gas-phase naphthalenes agreed with the amount found on parallel sorbent bed samplers operated at the same flow rate.

Because of the development of a new cleanup technique and the sensitivity of

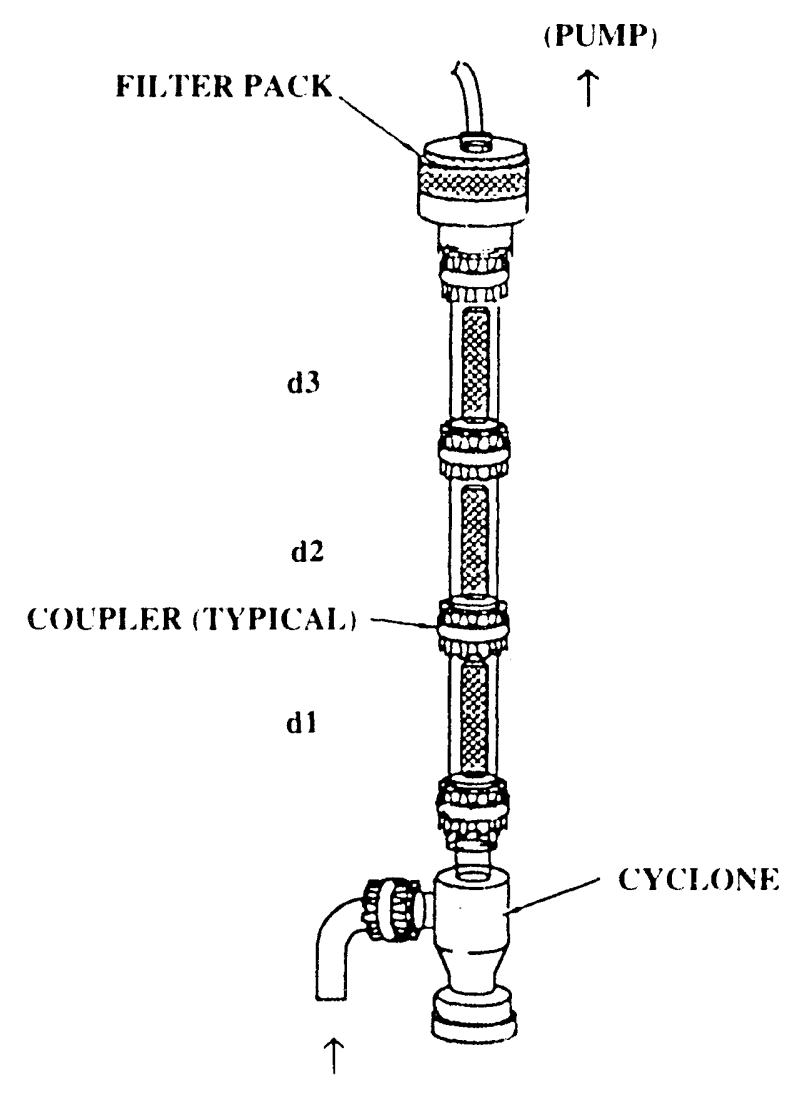

Figure 1.

Schematic diagram of the integrated organic z'apor particle sampler. 
a newly developed dual fluorescence detector high-performance liquid chromatography method, good precision has been obtained with the sampler, for determination of the phase distribution of PAH in indoor air and ETS, in as litthe as one hour of sampling. Detection limits (for sampling at $10 \mathrm{~L} / \mathrm{min}$ ) for phenanthrene, anthracene, pyrene and chrysene wer $10,0.5,0.1$ and $1 \mathrm{ng} / \mathrm{m}^{*}$ respectively, for gas-phase concentrations. Particulate phase detection limits for the same compounds were $0.2,0.6$, 0.1 and $0.3 \mathrm{ng} / \mathrm{m}^{\prime}$, respectively.

Preliminary results indicate that the phase distributions of these four compounds are significantly different when measured with the IOVPS, compared to a conventional sorbent bed sampler. For indoor air with no combustion sources, the gas phase concentrations of these compounds measured with the
IOVPS averaged about half of those found with a sorbent bed sampler. For ETS the concentrations of these compounds measured with the IOVPS averaged $70 \%$ of those found with the sorbent bed sampler. Since the IOVPS and the sorbent bed gave identical results with the most volatile of the semivolatile compounds (naphthalene), these results indicate that the sorbent bed was over-counting the gas-phase concentrations (i.e., had a positive artifact), and preceding filter was correspondingly undercounting the particle phase concentrations. The field testing program established that the observed differences in phase distribution were not due to sampling efficiency differences. The results indicate that the IOVPS can be used to determine phase distributions of $\mathrm{PAH}$ in indor air and ETS more accurately than has been possible with sorbent bed samplers.

"Proof of concept" has been established for the IOVPS. A patent application has been prepared for the coating procedure. During the next year, the IOVPS will be optimized further by use of a multi-channel configuration for the denuder. The IOVPS will be used extensively for measuring the phase distribution of $\mathrm{PAH}$ in environmental tobacco smoke.

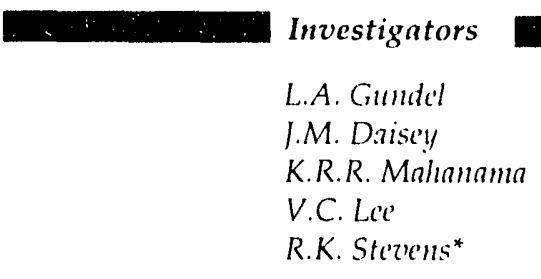

*U.S. Environmental Protectio: A Sency

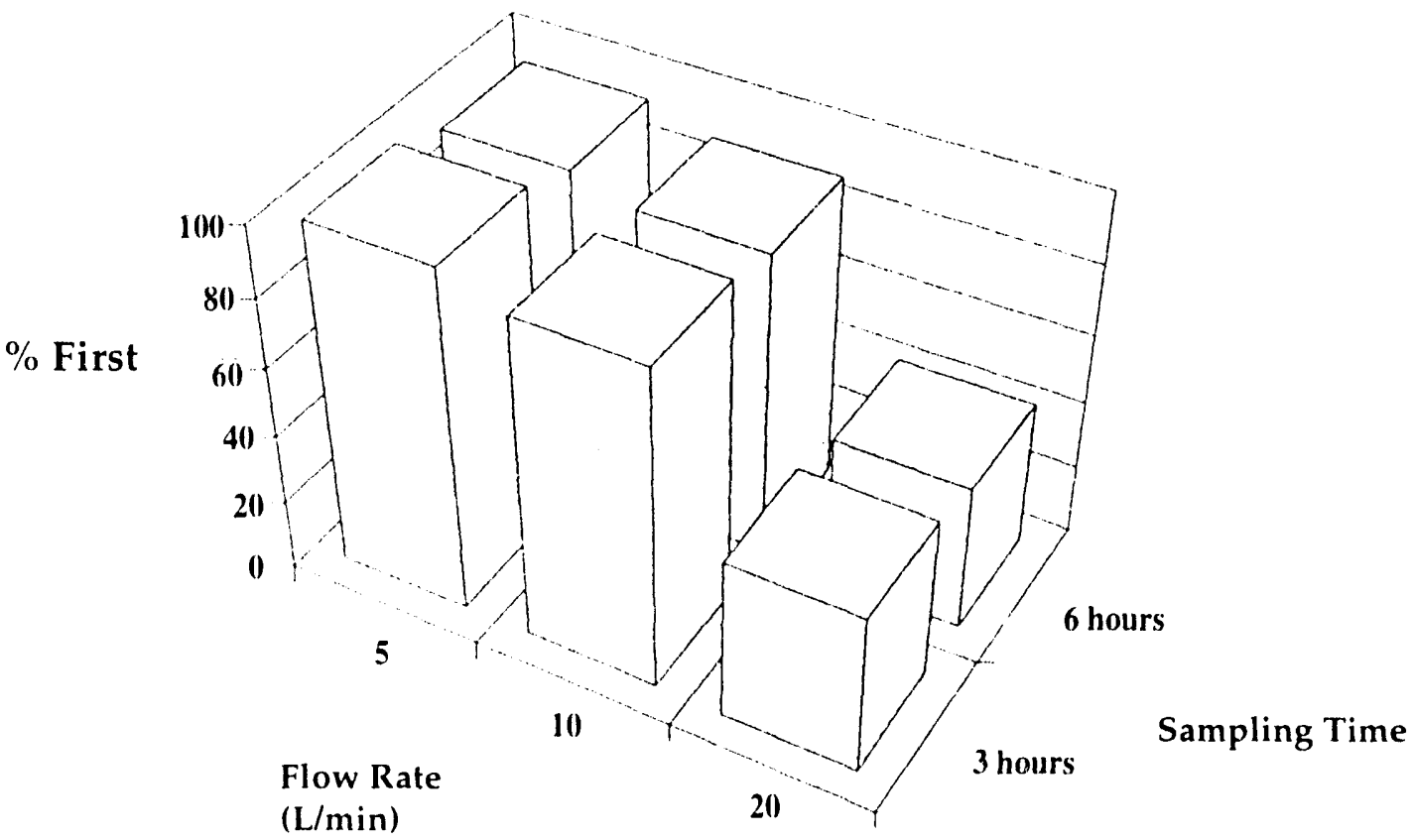

Figure 2.

Percent recotery of naphthalene and its methyl derizatize's on the first of thre'denuders, 'eresus flowe rate and sampling time'. 


\section{Modeling Emissions of Volatile Organic Compounds from New Carpets}

In a previous study, the amissions of selected volatile organic compounds (VOCs) from samples of new carpets were measured under controlled conditions in a $20-\mathrm{m}$ environmental chamber. The concentrations of the VOCs in chamber air were monitored for over a week after placing the samples in the chamber. The concentrations of most VOCs quickly reached a peak and then decayed rapidly over the first 12 hours of the experiments. After this period, the decay rates slowed, with emissions of most compounds continuing for the entire week. The dominant VOCs emitted by the carpets were, for the most part, constituents of the polymer backing materials. These observations suggested that the polymer backings were acting as diffusive sources of the VOCs released into the chamber air.

A simple physically-based diffusion model, which assumes that the emissions of VOCs originate from a finite layer of polymer backing material, is proposed to describe the chamber data. It is assumed that all of the resistance to mass transfer is within the polymer layer. The basic model parameters are the initial concentration of the VOC in the polymer backing, the diffusion coefficient for the compound in the polymer (D), and the partition coefficient of the compound between polymer and air $\left(K_{1}\right)$. Values for these parameters were obtained from the experimental data, and where possible, compared to literature values.

The experimental data and the bestfit model curves for a carpet with a styrene-butadiene rubber (SBR) latex backing are shown in the Figure. The concentrations of the VOC.s in the polymer backing at the beginning of the experiment and the polymer/air partition coefficients were independently obtained from experimental measurements. Therefore, the iterative parameter estimation procedure had only one degree of freedom in the diffusion coefficient, D, which was obtained by fitting the model to the transient chamber concentration data. The proposed model provides a reasonable fit to the data for the four compounds. The observed values of $D$ for these compounds are in good agreement with independently measured values for a range of VOCs in pure SBR. The observed values for $K_{1}$ are also in reasonable agreement with values independently determined in SBR.

The power of the proposed model lies in its ability to predict source strengths of VOCs into indoor air using a few physically meaningful parameters. Only one of these parameters is ot:tained by fitting the model to the concentration data. The model may also prove useful for improving carpet design and manufacturing procedures to reduce emissions.

Investigators

I.C. Littlic A.T. Hodgson A. Gadgil

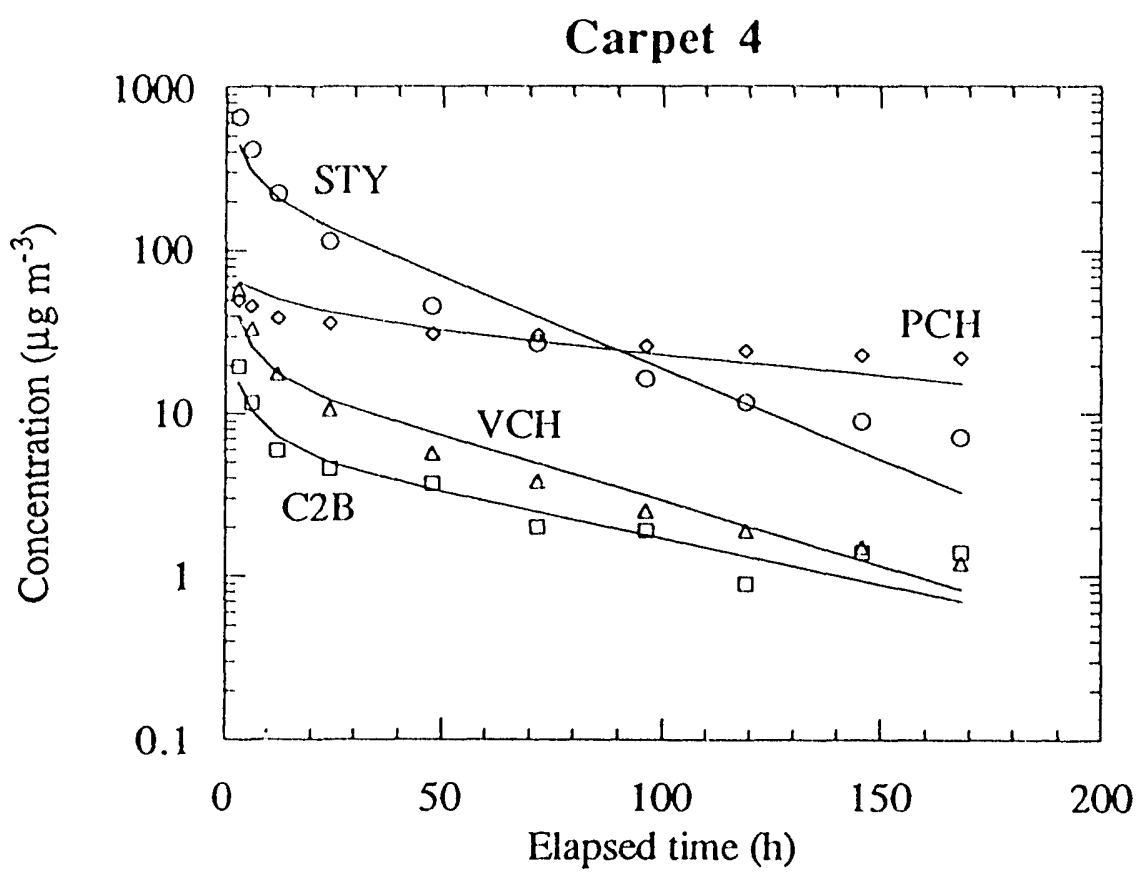

Figure.

Experimental chamber concentrations with time' and best-fit model curve's for carpet 4 with a SBR backing. STY = styrene; $P C H=4-p h e n y l c y c l o h e x e n e ; \quad V C H=4$-'thenyloyclohexine; and $C 2 B=$ ethylbenzene + xylenes. 


\section{Soil Sorption Kinetics}

There is mounting concern that populations living near contaminated sites and landfills may experience elevated exposures to volatile organic compounds (VOCs). Recent research (Hodgson et al., 1992; Little et al., 1992) shows that soil gas can be an important pathway for subsurface transport of VOCs into homes. Among the mechanisms governing the subsurface transport of VOCs, sorption onto soil grains plays a large role, as does the presence of moisture. To more closely examine the transport of VOCs in the relatively dry soil near houses, this study focused on the sorption of VOCs and water vapor orito individual soil grains.

Three soils were selected as representative adsorbents: a synthetic soil matrix, prepared by the EPA; a soil from a Superfund site; and sand. The organic carbon content, specific surface area,

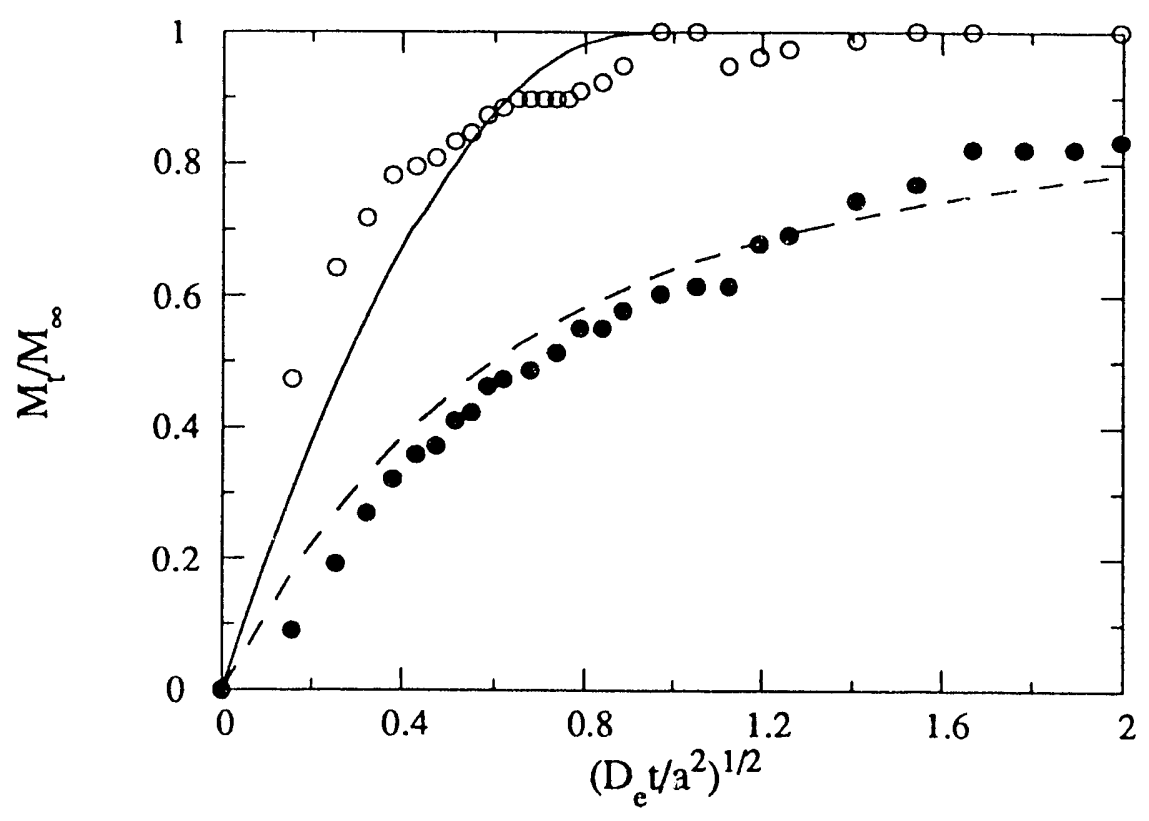

.. Figure.

Sorption kinetics for benzene at 650 ppm, onto SSm where $M t / M_{n}$ is the cumulative mass gain relative to that at equilibrium, $\left(D_{i} t / a^{2}\right)^{12}$ is the square root of dimensionless time, De is the effective diffusivity, $a$ is grain radius, and $t$ is time. Filled symbols denote desorption data. Model predictions are shown as a solid line for sorption, dashed line for desorption.

pore size distribution and grain density were measured, and the three soils were found to have significantly different properties. Two VOCs commonly found at contaminated sites, benzene and trichloroethylene, as well as water vapor were chosen as sorbate species. Sorption experiments were performed with a Cahn-1000 electrobalance enabling the determination of both sorption kinetics and isotherms. The gas-phase concentration of the VOCs was varied between $100 \mathrm{ppm}_{\mathrm{v}}$ and 1,000 ppm..

Water vapor was varied between a relative humidity of $10 \%$ and $90 \%$.

The sorption isotherms of VOCs onto dry soil were found to be non-linear, which is in contrast to the sorption behavior in saturated aqueous systems. The rates of VOC sorption and desorption on soil grains were relatively slow although sorption was found to be faster than desorption. A pore diffusion model accounted for the relatively slow kinetics. In addition, the asymmetry between the rates of sorption and desorption was resolved by coupling the non-linear Freundlich isotherm to an intraparticle diffusion model. For benzene, trichloroethylene, and water, the coupled model provided reasonably good fits to the experimental data for both sorption and desorption using only one adjustable parameter, an effective diffusivity (Figure). After allowing for Knudsen diffusion in small pores, the estimated pore diffusion coefficients were used to calculate tortuosity factors which lay in the physically reasonably range of 3 to 12 . This suggests that the model has a strong physical basis and that sorption kinetics could be predicted using only the sorption isotherm and a knowledge of the soil grain characteristics.
Investigators

T.-F. Lin

I.C. Little

W.W. Nazaroff 


\section{Pollutant Emission Rates from a Radiant Fiber-Matrix Gas Burner}

Pollutant emissions from combustion appliances can contribute significantly to indoor and outdoor air pollution. Individual unvented and malfunctioning combustion appliances can elevate indoor concentrations of pollutants such as carbon monoxide $(\mathrm{CO})$, nitric oxide (NO), nitrogen dioxide $\left(\mathrm{NO}_{2}\right)$, formaldehyde, and respirable suspended particles. In aggregate, the combustion appliances used in an urban community can significantly contribute to the levels of these pollutants in outdoor air.

Many air quality management districts in the United States are considering regulating pollutant emissions from domestic and commercial combustion appliances in an effort to comply with outdoor air quality standards. New combustion technologies are being developed to fill the need for new combustion devices with reduced $\mathrm{CO}$ and nitrogen oxide $\left(\mathrm{NO},=\mathrm{NO}+\mathrm{NO}_{2}\right.$ ) emissions. One such technology is the radiant fiber-matrix gas burner.

Experiments to quantify the emission rates of $\mathrm{CO}, \mathrm{NO}$, and $\mathrm{NO}_{2}$ from a prototype radiant fiber-matrix burner developed by Alzeta Corporation (Santa Clara, CA) were conducted in our laboratory. Various combustion conditions were tested by altering the adjustments of the fuel combustion rate and air/gas mixture. The pollutant emissions were measured under three test conditions with each condition being measured twice. Fuel combustion rates varied from approximately 20,000 to 32,000 $\mathrm{kJ} / \mathrm{h}$ and the air/fuel ratio varied from about $10 \%$ excess air to $40 \%$ excess air. The experimental equipment primarily consisted of a $27-\mathrm{m}^{2}$ environmental chamber and LBL's Mobile Atmospheric Research Laboratory. After a fifteenminute warm-up period, the gas burner was operated in the chamber until about $5500 \mathrm{~kJ}$ of fuel was consumed. The emission rates were calculated using a mass-balance model.

The measured pollutant emission rates were compared with those of convective and conventional infrared combustion appliances (Figure). The average $\mathrm{CO}$ emission rate ranged from 3.0 to $7.4 \mathrm{mg} / \mathrm{kJ}$, a factor of $5 \mathrm{to} 10$ times lower than convective burners. The average $\mathrm{NO}_{2}$ emission rate was almost an order of magnitude lower than convective burners, and was also lower than conventional infrared burners. Average $\mathrm{NO}$ emissions ranged from 1.1 to $6.5 \mathrm{mg} / \mathrm{kJ}$. This is similar to the NO emission rates from conventional infrared burners, but up to almost 30 times lower than convective burners.

The development of combustion appliances using new technology such as this may have an important future role in the reduction of $\mathrm{CO}$ and $\mathrm{NO}$. concentrations in both indoor and outdoor environments.

Investigators

M.G. Apte

G.W. Traynor

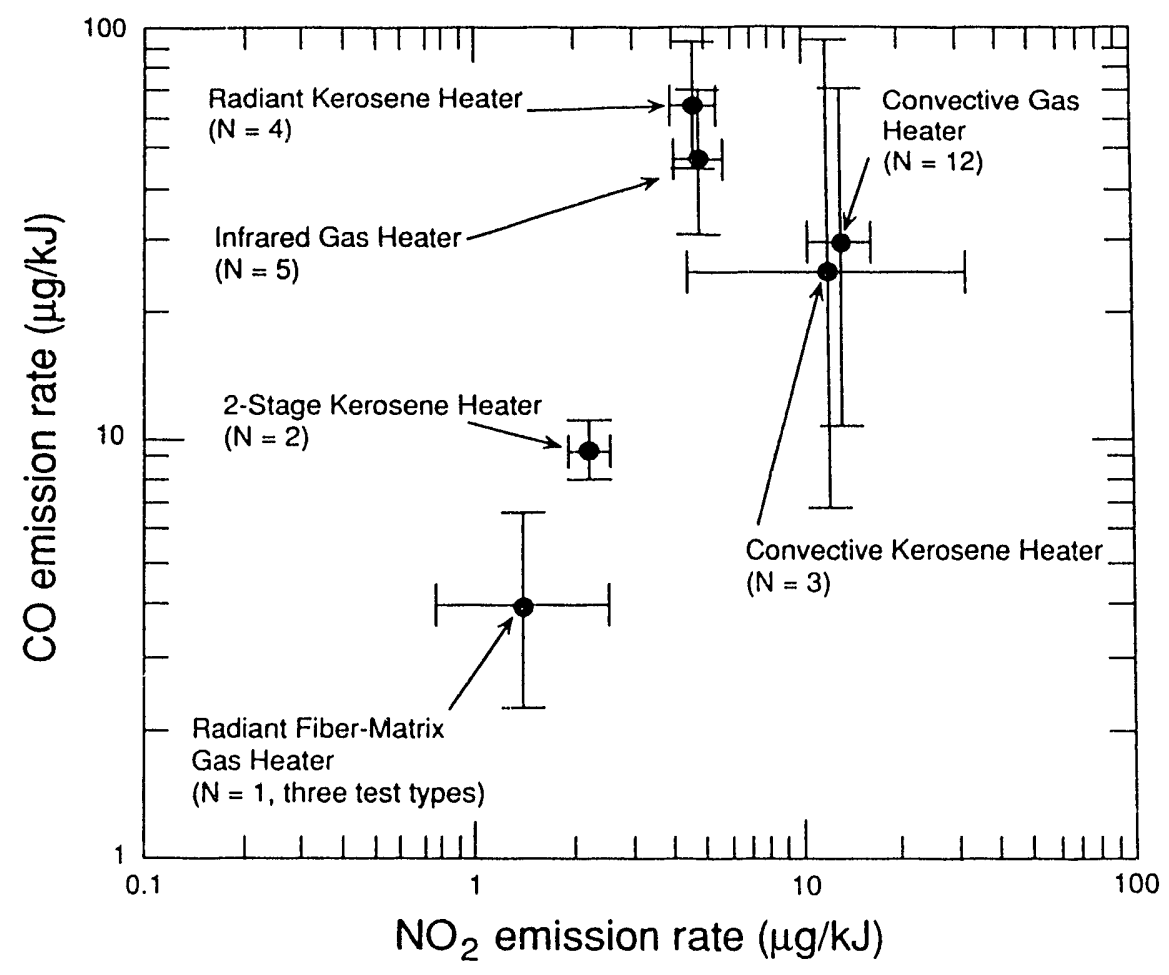

Figure.

$\mathrm{NO}_{2}$ and $\mathrm{CO}$ emission rates from convective and infrared une'nted gas space henters; convective, radiant, and two-stage kerosene heaters; and a prototype radiant fiber-matrix gas burner. The range bars, in log space, represent one standard derintion from the mean. Means and standard deviations are obtained from averaging the e'mission rates of separate heaters (except for the radiant fiber-matrix burner). For the' prototype fiber-matrix burne', the reported mean is derized from there' separate tests conducted under three different operating conditions. 


\section{Indoor Radon Research}

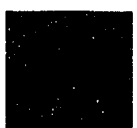

\section{A Comparison of Modeled and Measured Soil-Gas Entry into an Experimental Basement}

Advective flow of radon-bearing soil gas is the dominant source of radon in houses with elevated concentrations. Numerical models capable of accounting for characteristics of the soil and building substructure have been used to investigate the soil gas flows generated in response to the pressure differences between the radon entry points and the soil surface. Comparisons between the results of such models and the radon entry rates observed in actual houses are almost impossible to make because many of the details of the building-soil system that influence the flows are not known or cannot be easily incorporated into the model structure. These difficulties are often compounded by the variations in the driving pressures experienced in real houses.

The two small basement structures we have constructed in the Santa Cruz (CA) mountains provide an opportunity to compare results of the soil gas transport model with the observed flows and pressure fields. The pressure within the structure can be precisely controlled with respect to the pressure of the gas in the surrounding soil. Numerous probes extend outward from the structure into the surrounding soil, providing measurements of the pressure and radon concentration fields, as they may be influenced by the operational conditions of the structure. Soil gas and :adon entry occurs through precisely defined entry slots in the floor. The measured radon concentrations in the entry slots and in the strusture interior provide a relatively precise method of estimating the corresponding soil-gas entry rate. The comparison of the model and mea-

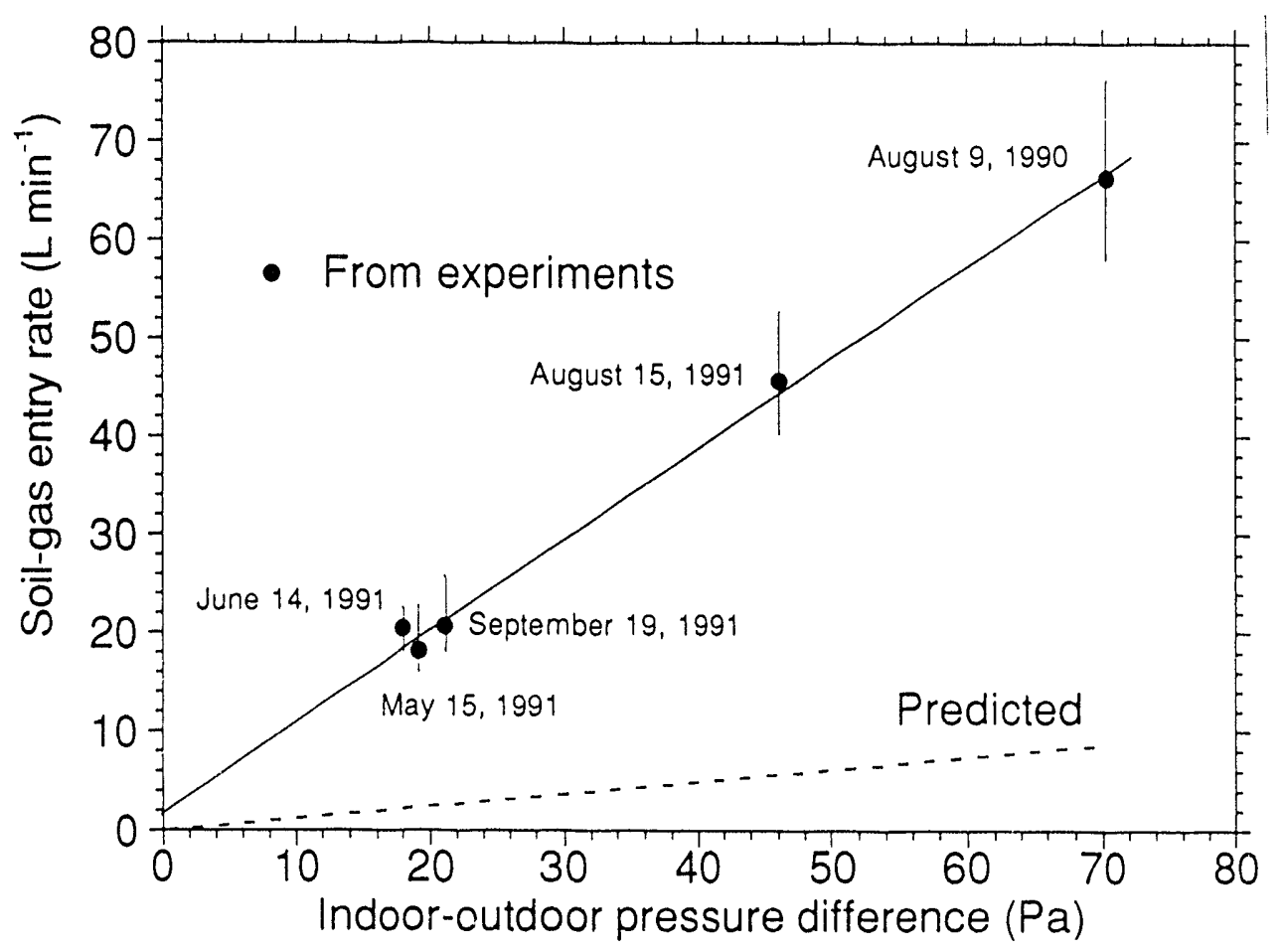

Figure.

Soil gas contry ratc as a function of structure depressurization. Solid circles indicate me'asured ralue's, with the vertical bars showing the maximum and minimum e'stimate's of e'ntry, based on the' experimental uncertainties and estimates of uncontrolled leakage into the structure. The solid line is a linear regression through the data. Predicted radon entry rate is indicated by the dashed line. 
surements described here was conducted for the structure with a gravel layer below the concrete floor slab (this layer is not present in the second structure).

Steady-state radon concentration measurements were made for a variety of structure depressurization conditions and during different seasons. Soil permeabilities were measured at all of the probes emanating from the structure, and an average soil permeability was obtained for the various soil regions surrounding the structure. The permeability of the subslab gravel layer was measured in the laboratory to be $2 \times 10^{-*}$ $\mathrm{m}^{2}$, approximately four orders of magnitude higher than that of the natural soil. These measured soil and gravel permeabilities were used as inputs to the numerical model.

Simulation of the soil gas flow and entry was done using a three-dimensional, finite difference model. Comparison of the modeled and measured pressurefields in the soil, as established by a steady-state depressurization of the structure ( $\mathrm{P}=-21 \mathrm{~Pa})$, shows important differences. In particular, the depressurization observed in the soil surrounding the structure was greater than predicted, especially at the mid-and low-wall level $2 \mathrm{~m}$ horizontally from the structure. Here the measured values exceed those predicted by factors of approximately 6 and 3 , respectively. The measured and predicted soil gas entry rate as a function of structure depressurization is shown (Figure). As expected, based on Darcy's Law, the flows are linear with the applied pressure difference, and for this soil and structure, the flow is $\sim 0.9 \mathrm{~L} \mathrm{~min}^{-1} \mathrm{~Pa}^{-1}$. As can be seen, the observed soil gas entry rate exceeds the predicted rate by a factor of 8 . These model-measurement discrepancies are currently under investigation. Another article in this annual report describes our measurements of soil permeability at larger scales, which may be one source of the underprediction of soil gas flow rates.

\section{Investigators}

K. Garbesi

R.G. Sextro

W.J. Fisk

M.P. Modera

K.L. Revzan 


\section{A Dynamic Pressure Technique for Estimating Permeability and Anisotropy of Soil to Airflow Over a Scale of Several Meters}

Persistent discrepancies between model predictions and measurements of soil-gas and radon entry into houses suggest that traditional in situ methods of assessing soil permeabilities to air might be yielding misleading results. The models consistently underpredict observed entry rates-a phenomenon that could be explained by consistent underestimation of regional soil permeability, the critical empirical input for determining the entry rate using soil-gas transport models. Soil permeabilities are typically assessed using a single probe technique that imposes a static pressure field emanating from the probc. In practice, these probes integrate information about soil characteristics out to a radial distance of about 10 to $50 \mathrm{~cm}$ from the probe sampling tip. We hypothesized that these small-scale measurements do not reflect soil permeabilities averaged over the several meters at which houses typically interact with soils.

To test this hypothesis, we developed a dual-probe, dynamic pressure technique to measure the effective permeability of soil to air on a scale of several meters. A sinusoidally oscillating pressure signal, imposed at a source probe, is recorded at a detector probe. The time lag between the imposed and detected signals is used to determine the effective permeability along the path between the probes. The time lag is determined precisely using a Fourier transform of the two signals and comparing the phase shift at the signal driving frequency. Appropriate selection of the detector probe location can indicate the existence of anisotropy in soil air-permeability. A field test of the dynamic pressure technique suggests that soil permeability at the test site does depend on sampling scale, with the longer-scale dynamic estimates of permeability exceeding the smallerscale static estimates by about a factor of six (Figure). The field experiment also indicated the presence of horizontalvertical anisotropy, with horizontal permeability exceeding vertical by a factor of 1.7 .

Experiments are planned to use this dynamic permeability technique to test the scale dependence of soil permeability in detail in different natural soils. This work should greatly improve our ability to accurately assess the potential for radon entry into houses.

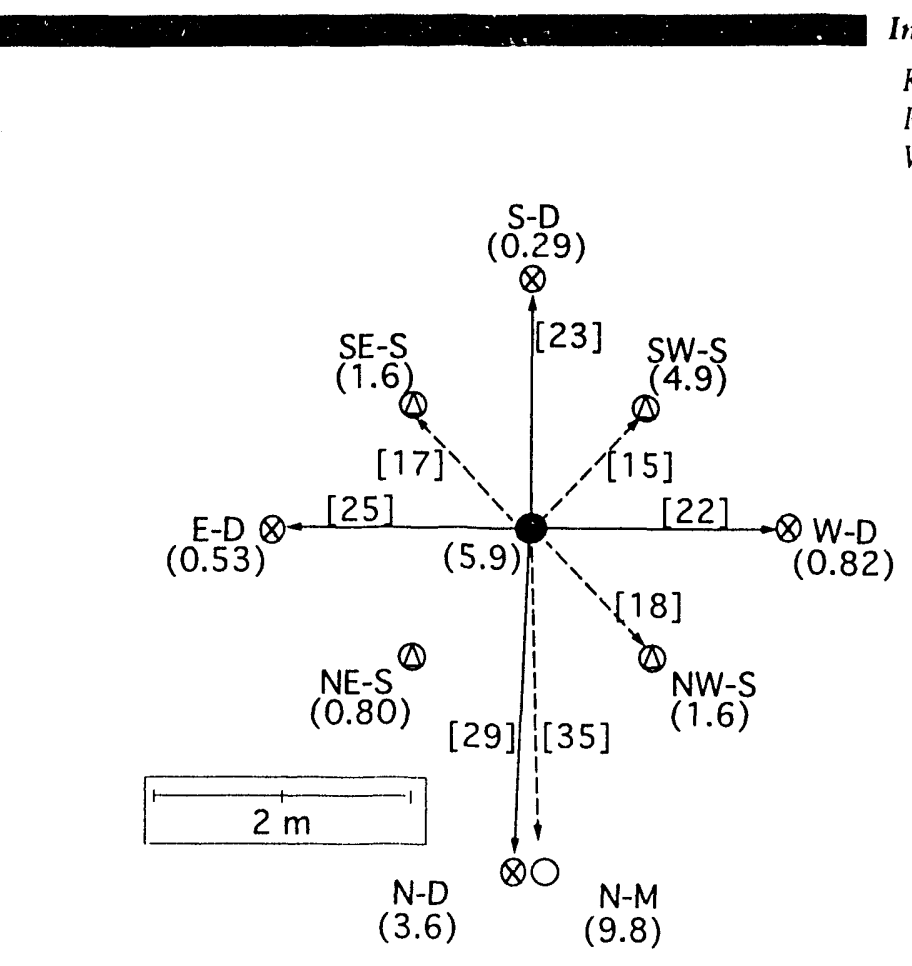

Investigators

K. Garbesi

R.G. Sextro

W.W. Nazaroff

\begin{tabular}{|l|l|}
\hline Source & Detector depths \\
depth $=2 \mathrm{~m}$ & $\bigotimes 2.0 \mathrm{~m}$ \\
& $\bigcirc 1.0 \mathrm{~m}$ \\
& $\bigotimes 0.6 \mathrm{~m}$ \\
\hline $\begin{array}{l}\text { [ - ] dual-probe dynamic measurements } \\
\text { ( -) single-probe static measurements }\end{array}$
\end{tabular}

Figure.

Plan view of field test site showing small-scale static measurements of soil permeability to air at soil probe locations and larger scale dynamic measurements indicated by arrows (solid = vertical measurements, nonsolid = nonvertical mensurements). All permeabilities in $10^{12} \mathrm{~m}^{2}$. 


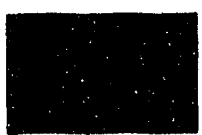

\section{Relative Effectiveness of Subslab Pressurization and Depressurization Systems for Indoor Radon Mitigation: Studies with an Experimentally Verified Model}

Advective entry of radon-bearing soil gas, drawn in by the slight depressurization of the house, is the dominant mechanism of radon entry into houses having high radon concentrations. The most common mitigation measure for indoor radon in such houses is the use of a subslab pressurization (SSP) or a subslab depressurization (SSD) system. These systems are widely used to limit radon entry into residential and nonresidential buildings.

Effective SSD systems decrease the pressure in the soil adjarent to the building foundation sufficiently to reverse the pressure gradients that normally drive soil gas entry. Joints at the junctions of concrete walls, slabs and totings, called wall-slab joints, are important locations for soil gas entry whore the pressure gradient must be reversed. Effective SSP systems substantially decrease radon concentrations in soil gas that enters buildings by forcing fresh air into the soil surrounding the house, and thus reducing the radon concentration in the soil near the foundation of the house. This is equivalent to ventilation of the soil with outdoor air. The SSD systems use fans and ducts to withdraw soil gas from beneath the slab floor and exhaust this soil gas to outdoors. In an SSP system, the direction of airflow is reversed.

Under most conditions, the soil-gas flow induced by the SSD or SSP system through the subslab gravel region is characterized by high Reynolds numbers, where the soil gas velocity is no longer a linear function of the pressure gradient. This is particularly true for regions near the subslab ventilation (SSV) system pit where air is withdrawn from (or supplied to) the region beneath the slab floor, and near the wall slab joints. This non-Darcy soil gas flow can adversely affect the extension of the depressurization field in the substab region, and thus the performance of the SSV system. The work described here elucidates some of these effects and has important consequences for the design and application of SSV systems.

A fully three-dimensional, finitedifference model was used to simulate the pressure-field and the flows of soil gas and radon in the subslab gravel layer and surrounding soil due to SSD and SSP system operation. Laboratory data relating pressure gradient to air velocity in subslab gravel samples were used as an input to the model. The model was subsequently verified by comparison with experimental data on subslab pressure field extension from SSV system operation in real houses.

We use the model to predict SSD and SSP system effectiveness for different soils and gravels, different magnitudes of applied pressure, and different effective widths of the slab-footer crack, using geometrical specifications of an idealized house with a basement. We show that a very permeable subslab aggregate layer significantly improves the performance of both the SSD and SSP systems, as does the sealing of the slab-footer cracks.

The figure (opposite page) illustrates the predicted reductions in radon entry rate (over the rate of radon entry in the absence of the SSD system) for a house equipped with an SSD system applying a suction of -250 pascals at a penetration in the slab. The percent reduction is shown in parentheses near each data point, for a variety of combinations of soil and subslab gravel permeabilities. Of course, increasing the applied pressure reduces the radon entry, but this can also increase the air change rate in the house. Except in the case of houses built on very permeable soils, SSD is predicted to be more effective than SSP in remediation of radon entry. The recommended system type, based on these simulations, is shown (Table).

\section{Investigators}

A.l. Gontril

Y.C. Bommefous

W.I. risk 


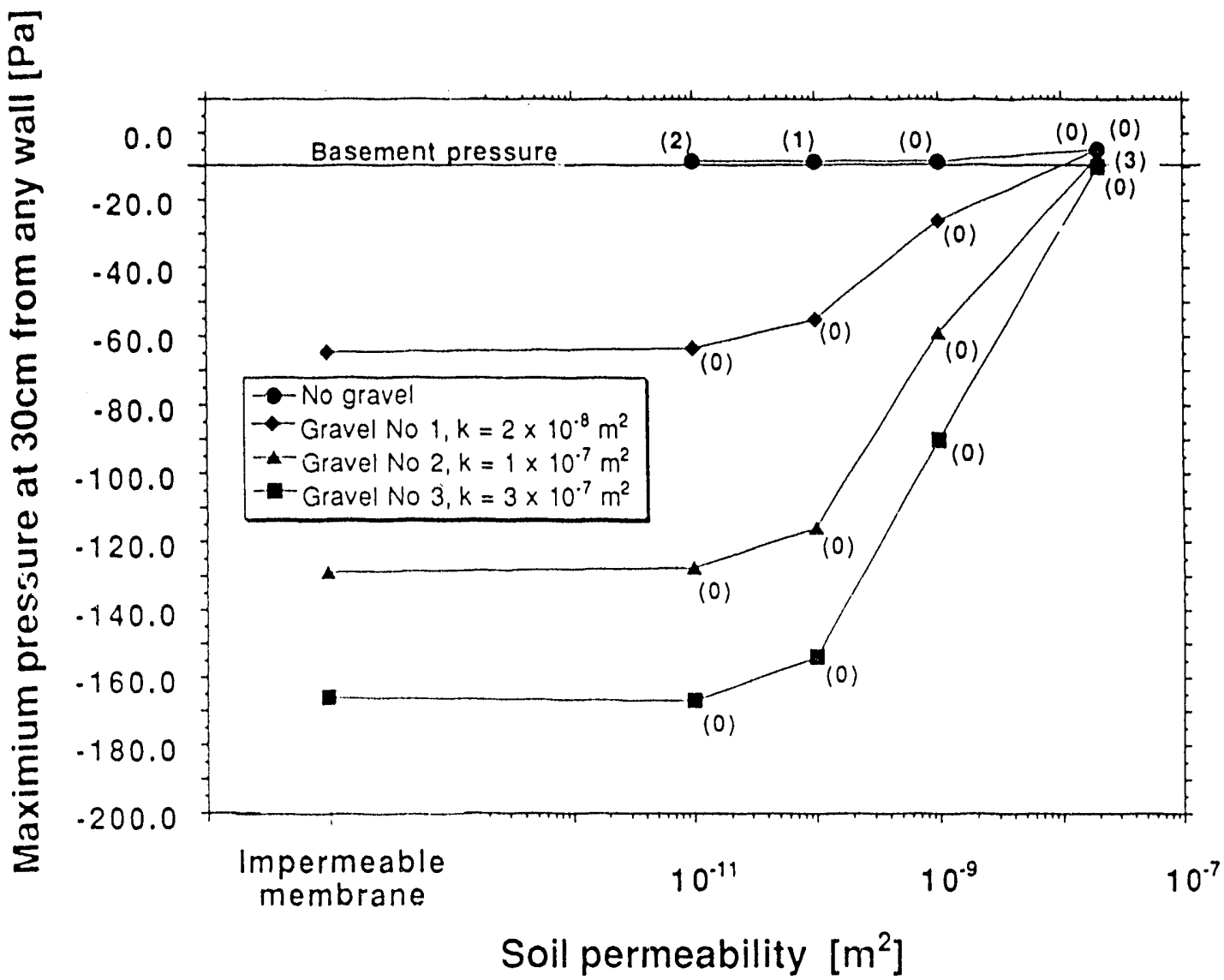

Figure.

Be'couse' SSD system performance depends on reversing the pressure gradient at the wall-slab crack, the maximum subslab pressure at 30 (m) from any urall is a good measure of SSD system performance.

Baseme'nt pressure' is at -10) Pa. predicted maximum subslab pressure at 30 $\mathrm{cm}$ from any wall is shoren as a function of soil permerability, for c'arious permeabilitites of subslab gravel (inse't hox), and for an impermerable'

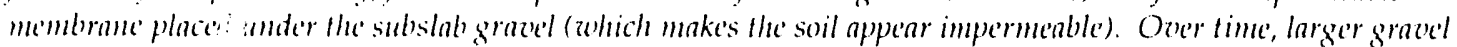
permealilitie's afford larger safety margins in the SSD system performance (e'g., against apperarance of additional cracks in the' basime'nt, slabl, degradation of SSD fan performance, or degradation of sealing around the SSD pipe').

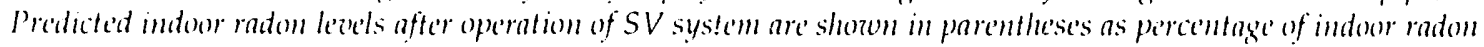
le'el's before' operotion of $S S \mathrm{~V}$ system.

\begin{tabular}{|c|c|c|c|c|}
\hline Soil Perm. $\left(\mathrm{m}^{2}\right)$ & $2 \times 10^{-8}$ & $1 \times 10^{-9}$ & $1 \times 10^{-10}$ & $\leq 1 \times 10^{-11}$ \\
\hline Gravel Perm. $\left(\mathrm{m}^{2}\right)$ & & & & \\
\hline No gravel & $\mathrm{SSP}$ & $\mathrm{SSD}$ & $\mathrm{SSD}$ & $\mathrm{SSD}$ \\
\hline $2 \times 10^{-8}$ & $\mathrm{SSP}$ & $\mathrm{SSD}$ & $\mathrm{SSD}$ & $\mathrm{SSD}$ \\
\hline $1 \times 10^{-7}$ & $\mathrm{SSP}$ & $\mathrm{SSD} / \mathrm{SSP}$ & $\mathrm{SSD} / \mathrm{SSP}$ & $\mathrm{SSD}$ \\
\hline $3 \times 10^{-7}$ & $\mathrm{SSP}$ & $\mathrm{SSD} / \mathrm{SPP}$ & $\mathrm{SSD} / \mathrm{SSP}$ & $\mathrm{SSD}$ \\
\hline
\end{tabular}

Table.

Recommended system configuration (SSD) or SSP') for (tarions soil and grancl perme'abilitie's, based on predicted system effectinene'ss. 


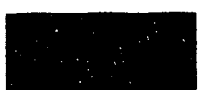

\section{Impact of Subslab Ventilation on Residential Ventilation Rates and Energy Costs}

Subslab ventilation (SSV) is one of the most effe tive and common methods of reducing indoor radon concentrations in houses with a basement. There are two basic methods of SSV: subslab depressurization (SSD) and subslab pressurization (SSP). In SSD, a fan is connected to one or more plastic pipes that penetrate the basement's slab fioor. The fan exhausts soil gas from beneath the slab to outside. This process decrease's the pressure beneath the slab, therefore reversing the pressure difference that normally causes soil gas and radon to flow into the basement through cracks in the floor. Electrical energy is required to operate the fan. In addition, the SSD system draws basement air through the cracks in the floor slab into the subslab region, increasing the ventilation rate of the house and the associated energy requirements for heating or cooling of ventilation air. In SSP, outdoor air is forced beneath the slab using a fan (i.e., the direction of air flow is reversed compared to that in an SSD system). SSP ventilates the soil beneath the slab and increases the pressure in this region of soil. SSP reduces the concentration of radon in the soil gas that enters the basement through cracks in the slab. The house's ventilation rate is increased because the SSP system causes an increased rate of flow into the basement from the subslab soil.

We used a validated numerical model to quantify the impacts of SSV systems on the ventilation rate of a prototype house located in the Chicago climate. Modeling was completed for a range of permeabilities of the soil and subslab aggregate, for various sizes of the cracks in the slab floor, and for two values of applied depressurization (or pressurization). The increased annual energy requirements were then calculated and capital costs and annual ener- gy costs were estimated assuming that the house was heated with electricity.

The modeling indicates that soil permeability, aggregate permeability, crack size, and SSV pressure substantially affect the degree to which SSV systems increase the ventilation rate. The impacts of SSD and SSP systems on ventilation rate were very similar. For buildings located in moderate-to-low permeability soils, SSV systems will typically increase ventilation rates (above a typical initial rate of 0.4 air changes per hour) by a factor of two or three. The initial capital cost of an SSV system is approximately $\$ 1100$. For the Chicago climate, a typical annual operating cost in 1992 is $\$ 175$, assuming that the house is not air conditioned and that the electricity price is $\$ 0.0786$ per kilowatt hour. (This includes the electricity use for the SSV fan and the energy use associated with increased ventilation from SSV operation.) With a projected real (above inflation) annual electricity price escalation rate of $0.12 \%$ and a 10-year planning horizon, the resulting net present cost of the SSV system is $\$ 2280$.

For comparison, we also modeled two methods of mechanical ventilation for reducing indoor radon concentrations: (1) mechanical exhaust ventilation; and (2) balanced (equal supply and exhaust) ventilation with heat recovery via an air-to-air heat exchanger. We show that exhaust ventilation is not effective in reducing indoor radon concentrations and that it may actually increase concentrations in some situations. Balanced ventilation with heat recovery is a viable option for reducing radon concentrations below the EPA's guideline of $150 \mathrm{~Bq} / \mathrm{m}^{3}$ only when the pre-mitigation radon concentrations are below approximately $1000 \mathrm{~Bq} / \mathrm{m}^{3}$. The net present cost of the balanced ventilation option, when it can be used, is sim- ilar to that of subslab ventilation.

Based on these assessments of effectiveness in controlling indoor radon concentrations, energy use, and costs, SSV systems are usually the preferred option for radon mitigation. However, SSV systems still consume substantial energy and many homeowriers will consider the costs of SSV tci be excessive. Lower-cost systems are needed.

Investigators

Y.C. Bonnefous

A.J. Gndgil

W.J. Fisk 


\section{Statistically Based Methodologies for Identifying High-Radon Areas of the United States}

It has been known for a decade that hundreds of thousands of people in the United States live in homes having radon concentrations of $20 \mathrm{pCi} / \mathrm{l}\left(740 \mathrm{~Bq} / \mathrm{m}^{3}\right)$ or greater, implying radiation exposures exceeding the occupational standards for radiation workers. Our program has been developing methodologies for identifying the areas of the United States where most of these high-radon houses occur. We found earlier that statistical models, based on the correlation between observed indoor levels and local data on radium concentrations and soils types, appear surprisingly successful in identifying highradon areas at the county level in Minnesota. We have been developing and testing such statistically-based approaches more comprehensively, and the effort has been joined by groups at the U.S. Geological Survey and the Research Triangle Institute.

Recent efforts have focused on three methodological issues: 1) the nature and effectiveness of differing statistical approaches, 2) the computer-based data handling and analysis systems that would support these approaches using the varied and substantial data bases that would be utilized, and 3 ) the availability and development of suitable data bases, including data on indoor radon concentrations and on local radium content, soil types, geology, housing characteristics, and meteorology.

We have used data from two states, Minnesota and New York, for developing and testing these miethodological components. The initial success for Minnesota with simple methodological approaches has set the stage for a more comprehensive treatment of data from this state, where we are exploring the potential for providing estimates of the indoor concentration distribution at the scale of individual census tracts (which have populations of about 4000 people). The case of New York provides the opportunity for exploring a somewhat more diverse setting, with somewhat lower indoor concentrations than Minnesota, with readily available computer-based data sets. We anticipate that we will soon lay the groundwork for examining data in two more areas of the country to demonstrate the application and effectiveness of the methodology in diverse geographic settings with substantial variation in observed indoor levels.

Successful development of this methodology, supported by both DOE/
OHER and the Environmental Protection Agency's Radon Division, would permit a near-term focus of the nation's radon control strategy of identifying and mitigating the homes with genuinely high levels. We shall also be able to examine carefully what goals might be practicably achieved for reducing the more typical indoor radon concentrations.

$\begin{array}{ll} & \text { Investigators } \\ \text { A.V. Nero } & \text { P.N. Price } \\ \text { M.G. Apte } & \text { K.L. Revzan } \\ \text { D.A. Nolan } & \text { H.A. Wollenberg }\end{array}$

Ro $(\mathrm{pCi} / \mathrm{o})$
0.06
0.12
0.18
0.24
0.30
0.36
0.42
0.48
0.54
0.60
0.66
0.72
0.79
0.84
0.90
0.96
1.02
1.08
1.14
1.20

Figure.

Radium concentration in the soil of Minnesota, based on data from the National Aerial Radiometric Reconnaissance conducted by the U.S. Department of Energy to assess U.S. uranium resources. The Indoor Environment Program uses this data to establish correlations with indoor radon concentrations. 


\section{Indoor Air Quality Controls}

\section{The Pollutant Control Index: Progress Toward a New Method of Characterizing Ventilation in Commercial Buildings}

Existing techniques for determining rentilation rates in commercial buildings include tracer gas stepups and decays, measurements of posi-occupancy $\mathrm{CO}$. decay rates, measurements of air flow rates, and mass-balance estimates based on measured $\mathrm{CO}$. concentrations and estimates of the rates that occupants gerierate carbon dioxide. None of these measurement techniques integrate over an extended time preriod (severoi days) although veritilation rate's may be temporally variable and iong-term average ventilation rates are often desirer. The tracer gas techniques are labor intensive and require stable rentilation raies Direct measurements of air flow rates are labor intensive and obtrusive. Post occupancy Co: decays are only applicable when all occupants leave the building within a short period. Fstimates or venthation rates based on $\mathrm{CO}$ mass balances are often inacicurate.

Seeking io overcoms these limitations, we introduce the concept that underities a new meihod of characterizing and measuring entilation and describe the measurement technique under invesilgation. Rather than determining a conventonal ventilation rate (i.e., arr charge per hour or flow: rate per occupani or unit flour area), the method deteimines how effectively the indoor corcentration of a simuiated pollutant is controlled during the period of occupancy at locetions where occupants breathe. The rutcome is a Pollutant Control Index (PCl). The PCl in normaliz d to account for the strength of the simuiated pollutant source and scaled to veleld a value of 100 for a hypothetical builcing with perfectly mixed indorr air and continu- ous ventilation at the rate $(10 \mathrm{~L} / \mathrm{s}$-occlipant and 7 occupants per $100 \mathrm{~m}^{2}$ ) specified in ASHRAE Standard 62-1989 entitled "Ventilation for Acceptible Indoor Air Quality."

The measurement procedure under development builds upon passive tracer gas techniques previously introduced in the U.S. and Sweden. The pollutant is simulated by multiple (e.g., 100) passive iracer gas sources distributed throughout a building and spaced uniformly per unit floor area. The sources emit tracer gas continuously and at approximately a constant rate, much like building materials emit pollutants but unlik: pollutant einissions from occupants). Indoor tracer gas concentrations are measured by collecting air / tracer samples on sorbent tubes at breathing loca. lions. In contrast to existing passive tracer techniques with continuous passive sampling, samples are collected actively (using pumps) only during the period of occupancy. Sample collection during the workday periods of multiple days should be possible. The scrbent tubes are analyzed by gas chromatographymass spectrometry. At present, we have developed a new type of passive tracer gas source and are evaluating sampling and sample analysis techniques. Field tests are planned to determine if measured ralues of $\mathrm{PCl}$ are substantially independent of the specific locations of tracer gas sources and samplers.

If the measurement technique is proven successful, measurements of the PCI will be advantageous for nany applications compared to traditional methods of measuring ventilation rate.
The measurement technique is relatively nonobtrusive. Manipulation of the ventilation system to stabilize the ventilation rate is not required. The measured $\mathrm{PCl}$ values integrate over time and automatically account for the schedule of operation of the ventilation system and the rate of air infiltration (both affect in. door pollutant concentrations). Finally, local values of $\mathrm{PCl}$ (e.g., at individual workstations) as well as buildingaverage values should be measurable.

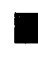

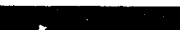

Investigators

W.J. Fisk

D. Faulkner

A.T. Hodgson

D. Sullia'nu 


\section{Use of an Air Vest to Reduce Worker Exposure and Improve Energy Efficiency in Industrial Fume Hoods}

Walk-in fume hoods (known also as spriay booths) are widely used in industry for removing airborne pollutants resulting from localized production activity such as spray painting or welding. Typically, a fume hood consists of a rectangular shaped enclosure, with one open side. The opposite side consists of a bank of filter pads beyond which is positioned an exhaust fan.

Fume hoods remove pollutants quite effectively when no worker is standing in the open face partially blocking the air flow. However, when the air flow is partially blocked by a worker, an eddy develops in front of the worker that draws some of the pollutant (commonly generated near and in front of the worker) towards the worker's breathing zone.

Increasing the face velocity of the fume hood increases the strength of the eddy almost in proportion, requiring large face velocities for effective reduction in the worker's exposure to the pollutants.

We have developed a device-the air 'cist-that either eliminates the backeddy downstream of the worker, or ventilates the region of the eddy. A small portable manifold on the worker's back draws air in and expels it from another small manifold positioned on the worker's chest. At high airflow rates through the air rest, the velocity of air exiting from the front manifold approximately equals the face velocity of the fume hood. This essentially eliminates the eddy. At much lower flow rates through the air vest, the recirculating eddy is not eliminated, but ventilation of the region containing the eddy is greatly increased. Both methods lead to a large reduction in pollutant concentration at the worker's breathing zone. The technique is also shown to be effecw'e in the absence of a back manifold to draw in air; in this case, the front manifold is supplied air from a stationary air supply near the worker.

The efficacy of the air vest was tested in experiments using a heated full-size mannequin and a full-scale walk-in fume hood. Sulfur hexafluoride, released at a small constant rate near and in front of the worker, was used to simulate pollutant generation during a work situation. The concentration of sulfur hexafluoride at several points near the worker was continuously sampled. Several experiments were conducted with different hood face velocities, different mass flow rates for air ejection from the front manifold, and with and without an intake manifold on the mannequin's back. The experiments show a reduction in the breathing zone concentration of the simulated pollutant by factors ranging from 100 to 800 .

If such a large reduction in exposure is not warranted, the face velocity of the hood can be reduced, without increasing worker exposure, by the use of this device. We calculate that in a Chicagolike climate, such a reduction would lead to annual energy savings (resulting from reduction in energy use for conditioning make-up air) of about $\$ 1200$ per fume hood per shift.

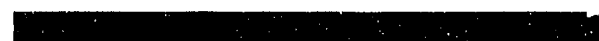

Investigators

$$
\begin{aligned}
& \text { A.J. Gadgil } \\
& \text { D. Faulkner } \\
& \text { W.I. Fisk }
\end{aligned}
$$




\section{Indoor Air Exposure and Risk}

\section{Issues in Evaluating Risks and Control Strategies for Radon and Other Indoor Pollutants}

The health risks estimated for indoor pollutants are often substantially larger than those for similar pollutants in outdoor air and water supplies, yet they are comparable to risks associated with occupational environments, and typically less than risks from accidents in homes or automobiles (Figure). This suggests the need to examine the premises and expectations for limiting risks in different environments-indoor, outdoor,

occupational-as a basis for evaluating the importance of risks, and formulating risk-limiting objectives, for indoor pollutants.

These environments differ in regard to such factors as who benefits from the setting or activity in question, who is affected by the associated exposures, and who has control or responsibility for the situation. Examining such factors as well as the magnitude and distribution of risks, for the case of radon (or other indoor pollutants) suggests a number of considerations in formulating a framework for evaluating isk, including:

- absolute versus relative magnitude of risk, from one situation to another,

- distribution of risks among the population and the associated question of controlling average versus high-level exposures,

- differing applicability of costbenefit criteria in different settings,

- portion of the estimated risk affected by different possible risklimiting objectives,

- priority given to different objectives in terms of time,

- degree of confidence that high-level exposure situations are identified,
- question of acting on "conservative" versus realistic risk estimates and of conservative versus practical strategic objectives,

- influence of contrasting environmental and economic situation in different countries,

- magnitude of risk from the pollutant itself versus that from synergism with some more important risk factor (such as smoking).

In general, such considerations suggest that it is not only the nature and magnitude of risk that is important in choosing objectives, but also the context, i.e., the type of setting in which the exposure occurs.

Many of these conceptual issues have not yet been developed adequately, and efforts are underway to establish the necessary interdisciplinary studies. In the interim, an effective near-term approach for radon is to give priority to high-exposure situations, providing the public with sound information and capabilities for monitoring and control, while aggressively trying to identify areas where most of the homes with unusually high concentrations occur. At the same time, a vigorous and careful effort to establish a conceptual framework for evaluating the significance of near-average radon exposures ought to be undertaken, while developing the control techniques and strategies for achieving long-term goals via changes in how new buildings are constructed (particularly in areas having high concentrations).

Investigator

A. V. Nere 


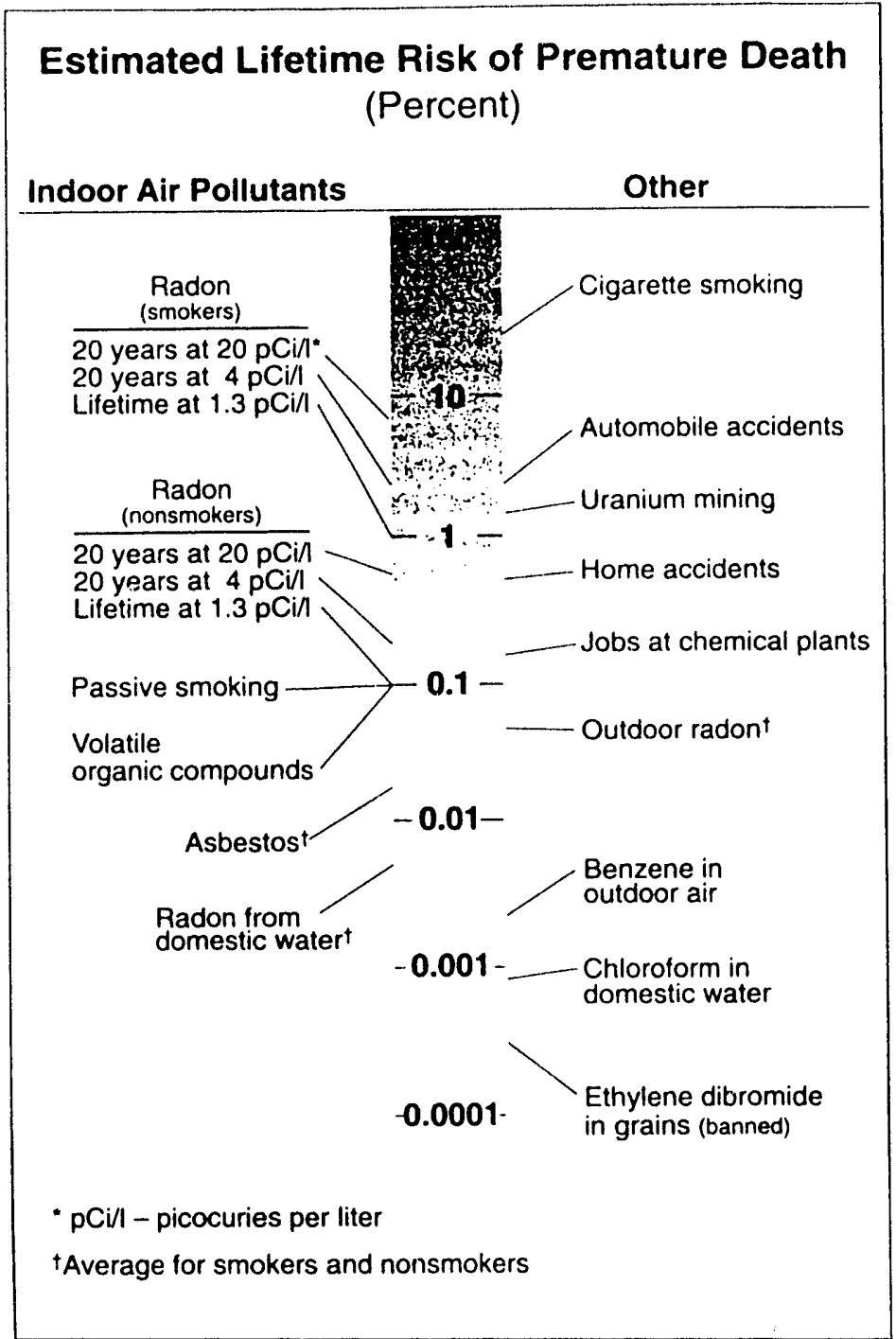

Figure.

Comparison of estimated lifetime risk of premature death (percent) from indoor air pollutants and from other risks. Risks are aterage for the whole population cxcept where indicated. Radon estimates presume a tenfold difference between smoker and nonsmoker risks due to synergism, but the exact mechanism is unknown. In the unlikely erent no difference exists between the two groups, the risk for the general population would be slightly below home accidents for a lifetime at $1.3 \mu \mathrm{Ci} / \mathrm{l}$, somezohat above home accidents for 20 years at $4 \mu \mathrm{Ci} / \mathrm{l}$, and aboue the risk from auto accidents for 20 years at $20 \mathrm{pCi} / \mathrm{l}$. 


\section{Indoor Ozone Exposure and Energy Conservation}

Despite considerable efforts throughout the past two decades, most urban areas in the U.S. remain out of compliance with federal air-quality standards for ozone. In Los Angeles, the standard was exceeded an average of 137 days per year between 1986 and 1989. When outdoor ozone levels are high, it is generally recommended that people remain indoors, based on the premise that indoor concentrations are lower than those outdoors. Existing data indicate that the indoor-outdoor concentration ratio varies from $<0.1$ to 0.8 . Considering this variability in indoor concentrations, and the fact that people in the United States spend as much as $90 \%$ of their time indoors, the goal of this research is to better understand the magnitude of indoor ozone exposures and the mechanisms that determine those exposures.

\section{Ventilative Cooling and Indoor Ozone}

The principal goal of our efforts this year was to evaluate the implications on indoor ozone concentrations of using ventilative cooling as an energy conservation strategy. The key issue is that the dominant source of indoor ozone is outdoor ozone, and indoor ozone concentrations are principally dependent on outdoor concentrations and indoor-outdoor air exchange rates. Therefore, strategies to reduce the need for refrigerative air conditioning that include increased ventilation (e.g., commercial-building economizers, residential window-opening, and evaporative cooling) pose the risk of creating significantly higher indoor ozone levels. Two additional goals were to better understand ozone removal and entry mechanisms, and to explore the implications of using activated carbon filters to reduce indoor concentrations. The approach employed to meet these goals included an extensive literature review, analyses of ozone removal pathways in building leaks and mechanical systems, and a detailed simulation of multizone air flows and ozone removal for timevarying weather and ozone concentration conditions.

Our research concerning the impact of ventilative cooling on indoor ozone indicated that ventilative cooling increases integrated indoor ozone exposures (ppb-hrs) approximately threefold

Table 1.

Ranch House Ozone Exposure, Computed During Occupancy 7AM-11PM)

\begin{tabular}{|lll|}
\hline Location, Operation and Assumptions & $\begin{array}{l}\text { Indoor Ozone Exposure } \\
\text { (ppb-hrs) }\end{array}$ & $\begin{array}{l}\text { Outdoor Ozone } \\
\text { Exposure } \\
\text { (ppb-hrs) }\end{array}$ \\
\hline Riverside, Closed Windows & 10900 & 251200 \\
$\begin{array}{l}\text { Riversife, Closed Windows, No Removal in } \\
\text { Buffer Zones }\end{array}$ & 21000 & 251200 \\
Riverside, Ventilative Cooling & 33400 & 251200 \\
San Jose, Ventilative Cooling & 29100 & 122400 \\
\hline
\end{tabular}


Table 2.

Commercial Building Ozone Exposure, Computed During Occupancy 8AM-6PM with LAX Weather and Ozone)

\begin{tabular}{|lll|}
\hline Operation & $\begin{array}{l}\text { Ozone Exposure } \\
(\mathrm{ppb}-\mathrm{hrs})\end{array}$ & $\begin{array}{l}\text { Annual Electricity } \\
\text { Consumption [million } \\
\text { kWh] }\end{array}$ \\
\hline No Economizer, No Carbon Filter & 11500 & 2.20 \\
No Economizer, Carbon Filter & 3700 & 2.21 \\
Economizer, No Carbon Filter & 25800 & 2.10 \\
Economizer, Carbon Filter & 8000 & 2.11 \\
\hline
\end{tabular}

both in residential and commercial buildings. More surprisingly, when using ventilative cooling in a residence, integrated indoor ozone exposures were predicted to be the same in San Jose, California, as in Riverside, California, despite the fact that integrated outdour ozone concentrations are approximately twice as high in Riverside (Table 1). This is because ventilative cooling can be used for more hours of the year in San Jose, even when outdoor ozone concentrations are high, which was not the case in Riverside. On the other hand, peak indoor ozone concentrations generally did not exceed outdoor standards, even when using ventilative cooling.

The two most interesting results of our examination of ozone entry and removal mechanisms were: 1) ozone removal in building leaks and air distribution systems depends principally on the surface materials in use, and is generally minimal and, 2) using a singlezone model to predict indoor ozone concentrations results in concentration predictions twice as high as those obtained when using a multizone model (for non-ventilative cooling). In addition, the use of activated carbon filters was simulated for a commercial building in Los Angeles, showing that indoor ozone concentrations could be reduced by a factor of three by using activated carbon filters. The additional fan energy required for these filters was found to be approximately one tenth of the energy saved by employing an economizer (Table 2).

\section{Future Directions}

Several future research challenges were identified over the course of this year's effort. These include the need for: 1) more research on actual use of window opening (ventilative cooling) in residences, 2 ) better examination of the impact of indoor air motion on ozone removal, 3 ) better examination of the ozone reaction probability of typical material surfaces, 4 ) better examination of the health effects of integrated lowlevel ozone exposures, 5) demonstration of activated carbon use in commercial economizer systems, and 6) use of time-activity patterns to determine overall exposure.

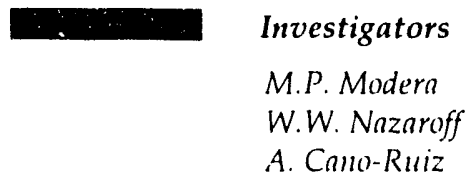




\section{Hypothesis-Based Research on the Causes of "Sick Building" Symptoms: A Design For Phases 2 and 3 of the California Healthy Building Study}

In the summer of 1990 , we completed Phase 1 of the California Healthy Building Study. We investigated twenty nine spaces within twelve city-or countyow'ned office buildings located in the San Francisco area. Eight hundred eighty occupants provided information on their health symptom prevalences, job, and workspace, and also provided personal information (e.g., sex, age, and smoking status). Building and ventilation system characteristics were determined with inspections and interviews. Several indoor environmental parameters were measured. The Phase 1 data indicated that occupants of the airconditioned and mechanically ventilated buildings had a higher prevalence of most symptoms relative to occupants of naturally ventilated buildings, although there was a substantial variation in symptom prev alence between buildings with the same type of ventilation. We know that ventilation type can not be a direct cause of symptoms, so it must be a surrogate for one or more direct causes such as an increased pollutant exposure. Other factors that were associated with increased prevalences of one or several symptoms include female gender, high job stress (reported on the questionnaire), use of carbonless copies, carpet in the test space, and no window' within 15 feet of the workstation. Based on data analyses to date, no measured environmental parameter was clearly associated with an increase in symptom prevalence.

We have designed two additional phases (Phase 2 and Phase 3 ) of research to be conducted in the buildings that were studied in Phase 1. Phase 2 activitie's, initiated in November 1992, are limited to inspections and low cost measurements that: 1 ) yield information that can be used in conjunction with the Phase 1 symptom data; or 2) permit a more efficient and directed third phase of research. Phase 3 , scheduled for the summer of 1993, will be a much more intensive investigation that includes substantial measurements and administration of a questionnaire on health symptoms.

Eleven hypotheses about the causes of work-related symptoms, some with associated sub-hypotheses, were selected for evaluation in Phases 2 and 3. Among the eleven hypotheses are the following:

- Hypothesis 1: Ventilation systems can be a source of volatile organic compounds (VOC), microbiological agents, or fibers that elicit symptoms.

- Hypothesis 2: Occupants' symptoms are caused by exposure to viable and non-viable microbiological agents, fibers, cleaning compounds, or insecticides that accumulate on indoor surfaces, especially high surface area materials. The exposure route may involve direct human contact with the surfaces or resuspension and inhalation of pollutants.

- Hypothesis 7: Elevated sensory irritation and respiratory symptoms due to gaseous contaminants can be predicted by a bioassay conduced by exposing mice to samples of indoor air.

- Hypothesis 9: Flicker from lighting is associated with the prevalence of headaches in office workers.

Specific research plans were developed to test each hypothesis. Features of the research plans that have not been included in our previous research efforts include an assessment of ind(x)r environmental parameters other than airborne pollutants or thermal conditions, a consideration of direct contact with pollutant sources as an exposure pathway, and use of bionssays. "Indoror Air Quality Program

Air and Industrial Hygiene Laboratory California Department of Health Services Berkelev, CA

Inestigators
W.J. Fisk
A.T. Hodgson
I.M. Macher Mendell'
D.M. Danis'y
'Industry. Wide Studies Branch
National Institute for Occupational Safety
and Health, Centers for Disedase Control
Cincinnati, OH
and Health, Centers for Disease Control 


\section{Development of a Carbon Monoxide Passive Sampler}

Every year in the United States, 15,000 to 20,000 carbon monoxide (CO) poisonings occur. Hundreds of these poisonings result in death, and thousands result in some type of physical or mental damage. In addition, a pregnant woman's exposure to high concentrations of $\mathrm{CO}$ can cause damage to the fetus. CO exposure can also damage the heart including causing the onset of heart attacks. High concentrations of $\mathrm{CO}$ can be caused by a wide variety of residential combustion appliances, including the following: unvented kerosene and gas space heaters; malfunctioning combustion space and water heaters; the indoor use of charcoal; and the indoor operation of an internal combustion engine (e.g., operating cars or generators in a garage). Some poisonings can be avoided by better education while others (e.g., those caused by malfunctioning vented appliances) can only be avoided by an active maintenance and repair program for combustion appliances. Of special concern are the poor and the elderly who often do not have the resources for routine inspection and maintenance of their gas or other combustion appliances.

There is a critical need for a low-cost $\mathrm{CO}$ sampling device for gas appliance diagnostic studies, indoor exposure studies, and targeted mitigation studies. A CO passive sampler would be the ideal measurement tool for such studies. Some of the goals of the CO passive sampler development research are to develop a passive sampler that would require no power, be suitable for deployment through the mail, be stable for several weeks before and after deployment, and have measurement errors (in accuracy and precision) of less than $20 \%$.
Our research program has concentrated on modifying a commerciallyavailable disk (Quantum Group Inc., San Dieg(), CA) that changes its transmission of near-infrared radiation in the presence of $\mathrm{CO}$. Working closely with the staff at Quantum Group, we have tested many new formulations of the disk to increase the sensitivity of the disks, to reduce the batch-to-batch variations, and to reduce the reversibility of the disks. To date, we have established the linearity of the sensors response to $\mathrm{CO}$, developed and tested a nonreversible formulation of the sensor, and tested new sensor substrates that are free from impurities. Developing a substrate without impurities has been a key to the development of a nonreversible $\mathrm{CO}$ passive sampler and has established the viability of our approach. Further refinements of the $\mathrm{CO}$-sensing disk and the passive sampler configuration are planned to optimize performance.

Investigators

G.W. Traynor

M.G. Apte'

G. Chang 


\section{Biologically Based Risk-Assessment Models}

In 1992 the risk assessment group has focused its efforts on the development of a toxicokinetic model for benzene in humans, and on the application of our newly developed cancer model to the statistical analysis of cancer bioassays.

Two papers were published this year on parametrization issues in toxicokinetics and on a application of our benzene model to the analysis of dose-rate effects. In the latter we investigated the effect of peak versus constant exposure levels, at typical workplace concentrations. The total amounts of several metabolites, directly involved in the carcinogenicity of benzene, increases by $20 \%$ on average during a peak exposure. Our work in the area provides a scientific base for the use of regulatory Short Term Exposure Limits (STEL.s) and the monitoring of exposure levels of toxicants in the environment.

Recent work involves the parametrization of the model for humans and the assessment of target site exposure at low dose rates. We show the occurrence of dose rate effects, even at low doses.

There appears to be virtually no saturability of the toxic pathway in humans.

To provide a complete framework for risk assessment we developed a discrete event model of carcinogenesis, of which a description and sensitivity analysis results were published this year (Figure). The model has been refined to include cell differentiation and we investigated the relative importance of inter-versus intra-individual variability in the cancer process. It appears that the usually un- observable intra-individual variability may in certain cases dominate the statistical variance of cancer bioassays. This finding casts doubt on the adequacy of the current procedures used to assess the population distribution of cancer potency and the value of safe dose limits. These results were presented to the annual meeting of the Society for Mathematical Biology.

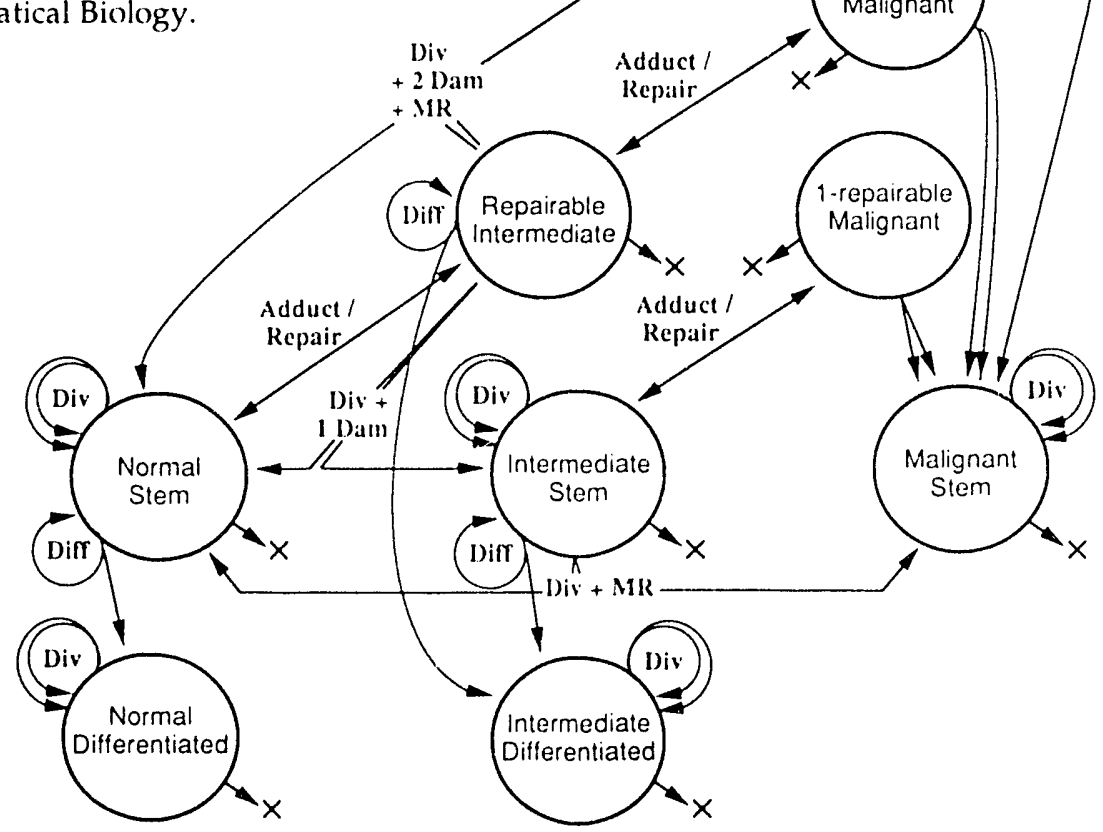

Figure.

Schematic description of events leading to formation of malignant colls, as implemented in the model. Key: Div = division; Diff = differentiation; $x=$ death; 1 Dam, 2 Dam = single and double' strand daringe'; Adduct/Repair = $D N A$ adduct formation or repair; $M R=$ mitotic recombination. 


\section{References}

Andersen CE. Entry of Soil Gas and Radon into Houses. Ph.D. Dissertation, Riso National Laboratory Report, Riso-R62.3(EN), Roskilde, Denmark, 1992.

Andrews JW, Modera MP. Thermal Distribution in Small Buildings: A Re'riew and Analysis of Recent Lit'rature. U.S. Department of Energy, Energy Conservation Report No. BNL 52349, 1992.

Apte MC, Traynor GW. Pollutant emission rates from a radiant fiber-matrix gas burner. Journal of the Air and Wasto Manugrement Association (in press).

Baughman AV, Gadgil AJ, Sextro RC, Nazaroff WW. Mixing of a Point Source Pollutant Within an Isolated Room. Proceedings of the 85th Anmal Merting of the Air and Wiaste Manuge'ment Association, Iune' 21-26, 1992, Kansas City, Missouri. Paper No. 92-79.109

Bauman FS, Helm RS, Faulkner D, Arens EA, Fisk WJ. Air Movement, Comfort, and Ventilation in Partitioned Workstations. Submitted to ASHRAE Joumal, 1992.

Bois FY, Compton-Quintana PJE. A discrete event model of carcinogenesis. Submitted to fournal of The'oretical Biology, 1992. (also published as Lawrence Berkeley Laboratory Report No. 321(16)

Bois $F Y$, Paxman DG. An analysis of exposure rate effects for benzene using a physiologically based pharmacokinetic model. Re'zulutory Toricology and Pharmacology, 1992: 15(2):122-136.

Bonnefous Y'C, Gadgil AJ, Allard F. Comparison of Effectiveness of Sub-Slab Ventilation Systems for Indoor Radon Mitigation: A Numerical Study. Lawrence Berkeley Laboratory Report No. LBL. 32280). To be published in the l'roced dings: of the Fifth Intermatomal facion's Cartier Comference. Oitober 7-9, 1992. Montreal. Cunturic.

Bonnefous YC, Cadgil AC, Fisk W). Impact of Subslab Ventilation Technique on Residential Ventilation Rate and Energy Costs. Tobe published in l'roctedengs of the 1.3th AlV Conference: Ventilation for Enery Effichency and Optimum Indoor Aer Quality, September 15-18, Nice, France. Air Infiltration and Ventilation Centre, Coventrs, Great Britain, 1992.

Bomefous YC, Cadgil AC, Fisk WJ, Prill RJ, Nematollahi AR. Field Study and Numerical Simulation of Subslab Ventulation Svitems. ES\&T 1992; 26 (4), 1752-1754.
Brager GS, Nero AV, Tien CL. Transport and Deposition of Indoor Radon Decay Products-I. Model Development and Validation. Atmosphicric Entironme'nt 1992; 25B(3), 343-358,

Brager GS, Revzan KL. Transport and Deposition of Indoor Radon Decay Products-II. Influence of Environmental Conditions. Atmospheric Environment 1992; 25B(3), 359.368.

Brimhall C.rl, Lewis CJ. Differential Element Trunsport in the Soil Profile at the Ben Lomond Small Structure Radon Site: A Geochemical Mass Balance Study. Department of Ceology and Geophysics, University of California, Berkeley, CA, 1992.

Cano-Ruiz JA, Modera MP, Nazaroff WW. Indoor ozone concentrations: Ventilation rate impacts and mechanisms of outdoor concentration attenuation. Presented at the 13 th Air Infiltration and Ventilation Conference, Nice, France, September 15 18, 1992. (Also published as Lawrence Berkeley Laboratory Report No. 32639, 1992.)

Diamond RC, McAllister JA, Rainer LI. Multifamily Enersyly Audit for HUD-Insured Multifamily l'ropertie's. I'repared for the Office of Multifamily Housing, U.S. Department of Housing and Urban Development, 1991

Diamond RC, McAllister JA, Rainer LI, Ritschard RL, Feustel HE. Affordable housing rehabilitation in Vermont: Energy savings, cost-effectiveness, and resident satisfaction. Presented at the Thermal Performance of the Exterior Envelopes of Buildings V, Clearwater, FL, 1992. (Also published as Lawrence Berkeley Laboratory Report No. 32167, 1992.)

Diamond RC, Pietle MA, de Buen O, Nordman B, Harris JP, Cody B. Energy use and energy savings: Measured results from the energy edge demonstration project. In:Prociedings of the 1992 Summer Study on Energy Efficiency in Buildings, American Council for an Energy Efficient Economy, Washmyton, D.C., 1992. (also published as Lawrence Berkeley Laboratory Report No. 32764)

Faulkner D, Fisk W], Sullivan DP. Indoor Air Flow and Pollutant Removal in a Roum with Desk-Top Ventilation. Submitted to ASHRAE. Transactoms, 1942.
Feustel HE. Peak power reduction potential for radiant cooling systems. In: Proceedings, ACEEE 1992 Summer Study on Energy Efficiency in Buildings. American Council for an Energy-Efficient Economy, Asilomar, CA, 1992.

Feustel HE, de Almeida A, Blumstein C. Alternatives to compressor cooling in residences. Energy and Building 1992;18.

Feustel HE, Dieris ]. A survey of air flow models for multizone structures. Encrgy and Buildings 1992;18.

Feustel HE, Huber K, Kula H-C, Luckau F. Air-Economizer Rating. Lawrence Berkeley Laboratory Report No. 30531, 1992.

Fisk WJ, Faulkner D. Air Exchange Effectiveness in Office Buildings: Measurement Techniques and Re'sults. In: Prepirints of the International Symposium on Room Air Convection and Effection'mess, July 22-24, Tokyo, pp. 282-295. Society of Heating, Air Conditioning, and Sanitary Engineers of Japan, 1992. (Also published as Lawrence Berkeley Laboratory Report No. LBL-331(13, 1992.)

Fisk WJ, Grimsrud DT. Indoor air controls. Accepted for publication as Chapter 4 in International Agrency for Re'search on Cancer Publication No. 109, Vol. 112, Indoor Air in the series Environme'ntal Corcinoyens, Methods for Analysis and Exposuric' Measurement, 1992.

Fisk WJ, Hodgson AT, Macher JM, Mendell MJ, Daisey JM, Faulkner D. Hypothe'sisBased Re'siarch on The Cause's of Sick Building Symptoms: 1 De'sign for Phase's 2 and 3 of the Califormia Healthy Building Study. Lawerence Berket'y Laboratory. Berkeley, CA,1992 (draft).

Fisk WJ, Modera MP, Sextro RG, Garbesi K, Wollenberg HA, Narasiminan TN, Nuzum T, Tsang YW. Radon Entry Into Bascments: Approach, Experimental Stractures, and Instrumentation of the Small Structure's Re'se'urch Project. Lawrence Berkeley Laboratory Report No. LBL-31864, 1992.

Gadgil AJ. Models of Radon Entry: A Review. Accepted for publication in Rudiation Protection Dosimetry, 1992. (Also) published as Lawrence Berkeley Laboratory Report No. LBL-331252, 1992.)

Gadyil $A G, B$ onnefous $Y C$, Fisk WJ. Relative effectiveness of subslab pressurization and depressurization systems for indoor radon mitigation: Studies with an experimentally verified model. In Proceredinges of the 1992 Symposimm on Radon and Radon Reduction Techolmology September 22-25, Minneapolis, MN, 1992. 
Gadgil AJ, Faulkner D, Fisk WJ. Rectuced Worker Exposure and Improved Energy Efficiency in Industrial Fume Hoods Using an Air Vest. To be published in Proceetings of IAQ' 92: Environments for P'ople', October 18-21, San Francisco, CA. Published by ASHRAE, Atlanta, GA, 1992.

Gadgil AJ, Kong D, Nazaroff WW. Deposition of Unattached $: P$ o and $: P b$ under Natural Concetion Flow in Enclosures: $A$ Numerical lneestigation. Accepted for publication in Radiation Protection Dosimetry, 1991. (Also published as Lawrence Berkeley Laboratory Report No. LBL-31098.)

Garbesi K, Sextro RG, Fisk WJ, Modera MP, Revzan KL. Soil Gas Entry Into an Experimental Basement: Model-Measurement Comparisons and Seasonal Effects. Submitted to ESET, 1992.

Garbesi, K, Sextro RG, Nazaroff WW. A Dynamic Pressure Technique for Estimating Permeability and Anisotropy of Soil to Air Flow Over a Scale of Several Meters. Lawrence Berkeley Laboratory Report No. LBL-32723. (Submitted to) ESET, 1992.)

Gundel LA, Mahanama KRR, Daisey JM. Silica cleanup of environmental tobacco smoke and airborne particles for determination of polycyclic aromatic hdrocarbons Paper No. 162, Extended Abstracts, 203rd National Meeting of the American Chemical Society, San Francisco, CA, April 5-10, 1992

Heerwagen JH, Diamond RC. Adaptations and coping: Occupant response to discomfort in energy efficient buildings. In: Procerdings of the 1992 Summer Study on Energy Efficiency in Buildings. American Council for an Energy Efficient Economy, Washington, D.C., 1992.

Heerwagen JH, Loveland J, Diamond RC Environmental satisfaction, coping and health outcomes in the office habitat. In:Procedings of the 1991 International Solar Enersy Society Conference, Denver, CO, 1991.

Hodgson AT, Garbesi K, Sextro RG, Daisey JM. Soil-gas contamination and entry of voldtile organic compounds into a house near a landfill. I. Air and Waste Manage' ment Assoctation 1992; 42(3), 277-283.

Little JC, Daisey JM, Nazaroff WW. Transport of subsurface contaminants into buildings: an exposure pathway for volatile organics. Environmental Science is Tethology 1992; 26: 2058-2066.
Little IC. Applying the two-resistance theory to contaminant volatilization in showers. Encironmental Sci Terlenol 1992;26: 1341-1349. (Also published as Lawrence Berkeley Laboratory Report No. LBL-31452, 1992.)

Little JC. Comment on "Human exposure to volatile organic compounds in household tap water: The indoor inhalation pathway." Environmental Sci Technol 1992; $26: 836-837$

Liu K-Sh, Chang Y-L, Hayward SB, Gadgil A], Nero AV. Estimating the Distribution of Lifetime Cumulative Radon Exposures for California Residents: A Brief Summary. Lawrence Berkeley Laboratory Report No. LBL-32179. Submitted to Radiation Protection Dosimetry, 1991.

Liu K-Sh, Chang Y-L, Hayward SB, Cadgil A], Nero AV. The distribution of lifetime cumulative exposures to radon for California residents. Submitted to fournal of Exposure Analysis and Environmental Épidemiology, 1992.

Mahanama KRR, Gundel LA, Daisey JM. Selective fluorescence detection of polycyclic aromatic hydrocarbons in environmental tobacco smoke and other airborne particles. Submitted to Analytical Chemistry, 1992. (Also published as Lawrence Berkeley Laboratory Report No. 32997, 1992.)

Meldem R, Meierhans R, Feustel HE. Can a simplified building description produce accurate results? In: Proceding's of the Intermational Congreses for Building Sertices Engineering, Hamburg, March 1992.

Mendell, MJ. Risk Factors for Work Related Symptoms in Northern California Office Workers. Lawrence Berkeley Laboratory Report No. LBL-32636, 1991.

Mendell MJ, Fisk WJ, Sinith A H, Seavev W, Hodgson AT, Daisey JM, Smith DF, Macher JM, Goldman L. Elerated Symptom Prevalence Associated with Mechanical Ventilation in Office Buildings: Findings from the California Healthy Building Study, Phase 1. Submitted to the Neri England lournal of Médicine', 1992

Modera MP. Skin temperature and evaporative heat loss variations for men and women in thermal comfort. Accepted for Publication in ASHRAE Trunsactions, 1992. (Also published as Lawrence Berkeley Laboratory Report No. 28925 . 1992.)
Modera MP. Zome Condotuning in Califormia Residences. Lawrence Berkeley Laboratory Report No. 30475, 1991.

Modera MP, Andrews f, Kweller E. A comprehensive yardstick for residential thermal distribution efficiency. In: l'roceddings, ACEEE 1992 Summer Stuty un Encrgy Efficioncy in Buildings. American Council for an Energy-Efficient Economy, Washington, DC, 1992.

Mumford JH, Lewtas J, Williams K, Tucker WC, Traynor CiW. Mutagenicity of organic emissions from unvented kerosene heaters in a chamber study. 1. Toxicolo.l Enironmental Health 1992; $36: 151-159$.

Nazaroff WW, Gadyil AJ, Weschler C]. Critique of the use of Deposition Velocity in Modeling Indoor Air Quality. Accepted for publication in Spercial Techuncal Publication (STP') of the' ASTM Symposinm on Modeling of Indoor air Quality and Exposure, April 27-28, Pittsburgh, 1992.

Nazaroff WW, Hung W-Y, Gadgil AJ, Sasse ACBM. Predicting Regional Lung Deposition of Environmental Tobaceo Smoke Particles. Submitted to Am. I. Public He'alth, 1992.

Nazaroff WW, Kong D, Gadgil AJ. Numerical Investigations of the Deposition of Unattached : $P(0$ and $: P b$ from Natural Convection Enclosure Flow. Lawrence Berkeley Laboratory Report No. L.BI.30249,1492. J. Acrosol Sci 1992; 23(4): 339352 .

Nero AV. A National Strategy for Indeor Radon. Issu's in Silence and Technology IX 1992; (1): 33-40.

Nero AV, Jr. Personal jmethods of controlling exposure to indoor air pollution. In: A. B. Tarcher, ed. Principles and Practice of Environmental Medicine'. New York: Plenum Medical Book Company, 1992; 533-548.

Offermann Ff, Loiselle SA, Sextro RC, Performance Comparisons of Six Different Air Cleaners Installed in a Residential Forced-Air Ventilation Sy'stem. In Proceedings of IAQ'91 Heallhy Buildings: American Society of Heating, Refrigerating and Air Conditioning Engineers, Allanta, CAA, 1991, pp. 342-350).

Offermann FJ, Loiselle SA, Sextro RC. Performance of Air Cleaners in a Residential Forced Air System. ASHRAE Jourmul 1992; $34(7)$ : 51-57. 
Piette MA, Harris JP, Diamond RC, Nordman B, deBuen O, Cody B. Evaluating savings from design predictions through measured performance in new, energy-efficient commercial buildings. In Procetings of the 5th International Enirgy Program Ernhation Conference. Chicago, IL, 1991.

Prill RJ, Fisk WJ, Gadgil AG. Factors that influence pressure field extension in new residential construction: Experimental results. In Procidings of the 1992 Symposium on Radon and Radon Reduction Tidmology, September 22-25, Minneapolis, $M N, 1992$.

Reddy TA, Cadsby KJ, Black HE, Harrje DT, Sextro RG. Modeling air flow dynamics in radon mitigation systems: A simplified approach. J. Air and Waste Manage'me'nt Association 41, pp. 1476-1482, 1991.

Revzan KL, Fisk, WJ. Modeling Radon Entry into Houses with Basements: The Influence of Structural Factors. Indoor Air 1992; 2(1): 4()-48.

Re'zan KL, Fisk WJ, Sextro RG. Modeling Raton Entry into Florida Slat-on-Grade" Houses. Lawrence Berkeley Laboratory Report No. LBL-32472. Submitted to Health l'hisils, 1942.

Revzan KL, Fisk WJ, Sextro RG. Modeling Radon Entru into Florida House's with Concrete' Slabs and Concrete-block Stem Walls. Lawrence Berkeley Laboratory Report No. LBL-30)05, 1991.

Sextro RG, Revzan KL, Fisk WJ. A modeling examination of parameters affecting radon and soil gas entry into Florida-style slabon-grade houses. In: Prociedmys of the EIA 1991 International Symposium on Radon and Radon Reduction Techolog!y, Paper V-1, Philudelphia, ['A, 1991.

Sextro RG, Fisk WJ, Wollenbery HA, Narasimhan TN, Flexser S, Gadgil A], Garbesi K, Modera M, Nuzum T, Revzan KL, Smith AR, Tsang YW. An Experimental and Theoretical Examination of Radon Transport and Entry at Two Small Basement Structures. Law'rence Berkeley Laboratory Report No. LBL-32396, 1992. Presented at the Natural Radiation Environment $V$ Conference, Salzburg, Austria, 1991.

Sherman MH, Dickerhoff DJ. ACT: Project Report: Ventilation and Air Tightness Measurement of the' Sunset Building. Lawrence Berkeley Laboratory Report No. LBL-31638, 1991
Spear RC, Bois FY, Woodruff T, Auslander D. Modeling benzene pharmacokinetics across 3 sets of animal data - parametric sensitivity and risk implications. Risk Analysis, 1991; 11(4):641-654.

Traynor GW, Apte MG, Diamond RC, Woods AL. A Corbon Monoxite Passiz' Sampler: Reseurch and Ditelopment Needs. Lawrence Berkeley Laboratory Report No. LBL-2688(), 1992

Tsang YW, Narasimhan TN. Effects of Periodic Atmospheric pressure variation on radon entry into buildings. Journal of Geophysical Re'sererch 1992; 97(6): 9161-9170.

Turk BH, Harrison J, Sextro, RG. Performance of Radon Control Systems. Eneryy and Buildings 1991; 157-175.

Turk BH, Prill RJ, Fisk WJ, Crimsrud DT, Sextro RG. Effectiveness of radon control techniques in 15 homes. I. Air and Waste Manage'ment Assoc. 1991; 41: 723-734, .

Weschler CJ, Hodgson AT, Wooley JD. Indoor chemistry: Ozone, volatile organic compounds, and carpets. Enrironmental Science and Te'dmology, 1992, 26: 2371-2377.

Woodruff TJ, Bois FY, Auslander D, Spear RC. Structure and parameterization of pharmacokinetic models-their impact on model predictions. Risk Analysis, 1992; 12(2): 189-201.

Zinbo M, Schuetzle D, Hsieh DPH, Kado NY, Daisey JM, Gundel LA. An improved fractionation procedure for the bioassaydirect chemical analysis of air particulate extracts. Analytical Silence's 1992; 8: 461468. 


\section{Projects described in this report were supported by the following sources:}

- U.S. Department of Energy:

Assistant Secretary for Conservation and Renewable Energy:

Office of Building Technologies

Building Systems and Materials Division

Building Equipment Division

Assistant Secretary for Environment, Safety and Health, Office of Environmental Analysis

Director, Office of Energy Research, Office of Health and Environmental Research

- National Institute of Envi:onmental and Health Sciences (NIEHS), National Institutes of Health

- National Heart, Lung and Blood Institute, National Institutes of Health

- U.S. Environmental Protection Agency

- U.S. Food and Drug Administration

- U.S. Consumer Product Safety Commission

- California Institute for Energy Efficiency (CIEE), a research unit of the University of California. (Publication of research results does not imply CIEE endorsement of or agreement with these findings, nor that of any CIEE sponsor.)

- Cigarette and Tobacco Surtax Fund of the State of California, through the Tobacco-Related Disease Research Program of the University of California

- Electric Power Research Institute, Palo Alto, CA

- Gas Research Institute, Chicago, IL

- Alzeta Corporation, Santa Clara, CA

- Central European University, Budapest, Hungary

- Carl-Duisberg Gesellschaft, Federal Republic of Ciermany

- Meierhans \& Partner AG, Switzerland

- University of Sheffield, UK

- Lawrence Livermore National Laboratory

This support was provided through the U.S. Department of Energy under Contract No. DE-AC03-76SF00098. 

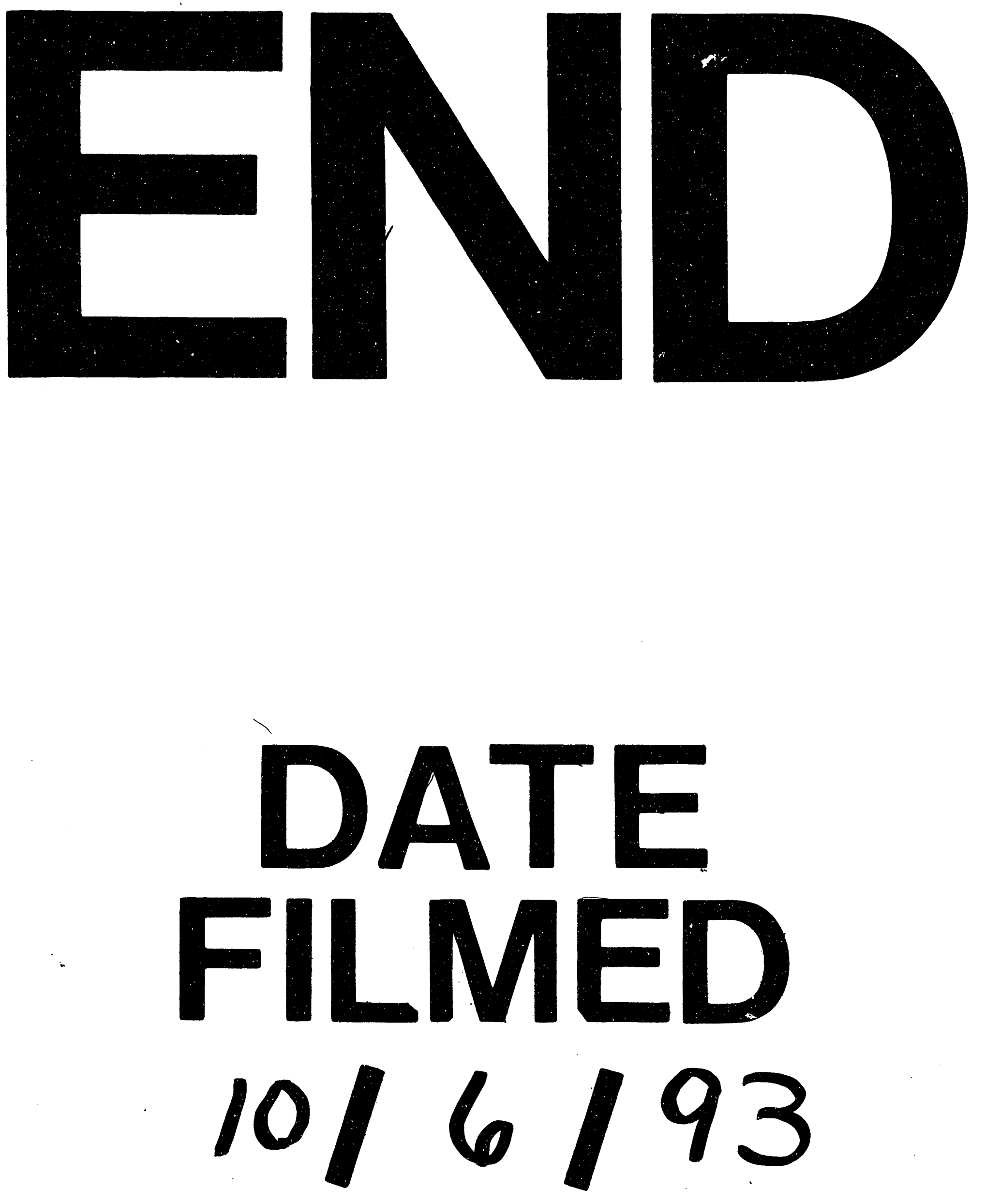

1 